\title{
THE EFFECTS OF UNEMPLOYMENT INSURANCE BENEFITS: NEW EVIDENCE AND INTERPRETATION
}

\author{
Johannes F. Schmieder \\ Till von Wachter \\ Working Paper 22564 \\ http://www.nber.org/papers/w22564
NATIONAL BUREAU OF ECONOMIC RESEARCH
1050 Massachusetts Avenue
Cambridge, MA 02138
August 2016

We are grateful to Sascha Drahs, Matthew Gudgeon, Kavan Kucko and Josef Zweimueller for many valuable comments. The views expressed herein are those of the authors and do not necessarily reflect the views of the National Bureau of Economic Research.

NBER working papers are circulated for discussion and comment purposes. They have not been peer-reviewed or been subject to the review by the NBER Board of Directors that accompanies official NBER publications.

(C) 2016 by Johannes F. Schmieder and Till von Wachter. All rights reserved. Short sections of text, not to exceed two paragraphs, may be quoted without explicit permission provided that full credit, including $\odot$ notice, is given to the source. 
The Effects of Unemployment Insurance Benefits: New Evidence and Interpretation

Johannes F. Schmieder and Till von Wachter

NBER Working Paper No. 22564

August 2016

JEL No. H21,H53,J64,J65,J68

\begin{abstract}
The Great Recession has renewed interest in Unemployment Insurance (UI) programs around the world. At the same time, there have been important advances in both theory and measurement of UI. In this paper, we first use the theory to present a unified treatment of the welfare effects of UI benefit levels and durations and derive convenient expressions of the disincentive effect of UI. We then discuss recent estimates of the effect of UI benefit levels and durations on labor supply based, to a large extent, on high-quality research designs and administrative data. We relate these estimates directly to the sufficient statistics identified by the model. We also discuss several active and open areas of research on UI. These include the effect of UI on aggregate labor market outcomes, the effect of UI on job outcomes, the long-term effects of UI, the effects of UI under non-standard behavioral assumptions, and the interactions of UI with other programs. While our review of the new experimental estimates confirms the range of negative labor supply effects of the previous literature, we show based on the model that these estimates are imperfect proxies for the actual disincentive effects. We also isolate several important areas in need for additional research, including estimates of the social value of UI as well as the effects of UI in less-developed countries.
\end{abstract}

Johannes F. Schmieder

Department of Economics

Boston University

270 Bay State Road

Boston, MA 02215

and IZA

and also NBER

johannes@bu.edu

Till von Wachter

Department of Economics

University of California, Los Angeles

8283 Bunche Hall

MC 147703

Los Angeles, CA 90095

and NBER

tvwachter@econ.ucla.edu

A Online Appendix is available at

https://sites.google.com/site/johannesschmieder/EffectsofUI_WebAppendix.pdf?attredirects=0\&d=1 


\section{INTRODUCTION}

The Great Recession brought job loss and unemployment rates in many countries up to historically high levels. This created renewed interest among policy makers and economists in the design of unemployment insurance (UI), which typically constitutes the most important system to help jobless workers. It has long been recognized that while UI provides a clear welfare benefit by offering insurance and consumption smoothing that is unlikely to be provided by private markets ${ }^{1}$ UI benefits also come at the cost of distorting incentives to look for a job. A sizable literature from the 1970s to 1990s estimated the magnitudes of these costs and benefits and these papers have been summarized in excellent reviews, for example by Meyer (2002) and Krueger and Meyer (2002). However, recent years have seen a surge in renewed interest in UI, partly driven by the availability of new data and research designs. This research has led to significant new empirical findings as well as new theoretical insights into the effects of UI.

In this paper, we provide a review of the key findings on the effects of UI that have emerged from this recent literature. A central theme in this research has been the goal to connect the study of the effects of UI to welfare analysis. Chetty (2008) - building on work by Baily (1978) - showed how a public economics model of UI can be used to derive which behavioral parameters are key to understanding the welfare effects of UI in the spirit of the so-called sufficient statistics approach. We develop a tractable version of the Baily-Chetty model that allows us to characterize the welfare effects of both UI benefit extensions and changes in benefit levels in a unified framework. Using this model we derive the monetary efficiency loss from providing one additional dollar of UI transfer and show how typical estimates of the labor supply effects of UI are only imperfect proxies of this parameter. This parameter can be more easily compared between studies and can be implemented with existing data. We then use the model to guide our discussion of various theoretical extensions in the recent literature on UI. This work includes the importance of spillover effects in the labor market, the role of other job outcomes, such as reemployment wages, and new insights from behavioral economics.

The recent literature has been shaped by the availability of large administrative data

\footnotetext{
${ }^{1}$ See Hendren (2015) for a discussion of and evidence that unemployment insurance could not be sustained as a private insurance scheme due to adverse selection.
} 
sets and an emphasis on design-based estimation strategies exploiting sharp discontinuities in UI durations and kinks in UI benefit schedules. These estimates have greatly improved the plausibility and internal validity of estimates of the labor supply effect of UI parameters. The advances in estimating labor supply effects has helped to highlight several additional key questions cannot be easily answered with existing research designs. For example, the literature on spillovers has stressed the importance of estimating effects on the macro level, which is not possible in a regression discontinuity or regression kink design. Another example is that the welfare-enhancing side of UI depends on the consumption smoothing effects of UI, but consumption is rarely available in administrative data sets. Finally, understanding the mechanisms of job search, such as the role of learning, or behavioral aspects like reference dependence or biased beliefs, would be greatly helped by direct micro data on these aspects of job search, in addition to information on outcomes like accepted jobs and wages. While the recent literature represents important advances in all of these areas, there is much room for future progress.

In the next section we provide a short overview over the features of a typical UI system, while highlighting some of the variation observed across countries. In Section 3, we derive convenient expression of the welfare costs of a transfer of a dollar of UI benefits to the unemployed. In section 4, we first summarize the key results from the empirical literature and discuss their implications in the Baily-Chetty model, as well as various key extensions and applications of this framework. Section 5 briefly discusses various other areas or active research in UI, such as spillovers between programs or insights from behavioral economics, with a particular emphasis on open questions that could be addressed in future work. In Section 6 we conclude.

\section{THE STRUCTURE OF UNEMPLOYMENT INSURANCE SYSTEMS}

About 72 countries worldwide - including all OECD countries - have some form of Unemployment Insurance (UI) designed to financially support unemployed individuals while they search for a job.2 While programs differ across countries, most UI systems exhibit a similar broad structure that determines eligibility, coverage and generosity of benefits.

\footnotetext{
${ }^{2}$ This section draws heavily from Carter et al. 2013 as well as the OECD (2015): http://www.oecd.org/els/benefits-and-wages-statistics.htm
} 
The typical UI system is a mandatory insurance system run at the national or state level that covers all salaried workers in the formal sector, with some variation in the coverage of public employees and the self-employed..$^{3}$ UI eligibility of an individual entering unemployment is typically determined by two types of criteria: a) meeting certain employment history requirements and b) the reason for being unemployed. The first set of eligibility criteria typically consist either of a minimum amount of previous work, sometimes at a minimum income level, or of a minimum amount of contributions to the UI system. Often countries require either six or twelve months of contributions over a certain specified period of time (such as 2 years prior to unemployment), in order to qualify for UI . In the United States, states typically require at least 20 weeks of employment, as well as a minimum amount of earnings over a baseline period prior to unemployment. The second set of eligibility criteria consists of requirements regarding reasons for becoming unemployed / leaving a job. Accepted reasons for becoming unemployed usually consist of being laid-off due to economic or business reasons, but most countries also accept being forced to leave employment due to unpaid wages, harassment, dangerous working conditions, or other misbehavior by the employer 4

An unemployed individual may face a waiting period before being able to receive benefits, which ranges between 0 days (such as the US, Germany or Belgium) and 14 days (Canada). This waiting period effectively serves a similar purpose as a deductible in other forms of insurance by forcing individuals to bear some of the costs of unemployment. It also helps reduce the burden from processing very short UI claims. After the waiting period, individuals are eligible to receive benefits up to the potential benefit duration or potential benefit duration (PBD). The PBD varies significantly across and within countries. Within countries, PBD is often a function of duration of past contributions and sometimes varies with the age of the unemployed. In the US, the PBD is uniform for all workers within a state, but can vary across states. In contrast, for example in Argentina, 6 months of contribution duration generate a PBD of 2 months, which can increase up to 12 months for contribution durations of at least

\footnotetext{
${ }^{3}$ Two interesting exceptions are Denmark and Finland, where UI is a voluntary program that is subsidized by the government. Another interesting example is Chile, where individuals benefits are drawn from individual UI savings accounts which are supplemented by a traditional insurance component.

${ }^{4}$ Workers who become unemployed due to voluntary quits, or because they are fired for misconduct are sometimes still eligible for benefits, but may face sanctions, such as lower benefit levels (Thailand) or a considerable waiting period before receiving UI benefits (e.g. three months in Germany and Japan, or four months in France).
} 
36 months. Furthermore the unemployed over 45 can receive an extra 6 months of benefits. Similarly, PBD in countries like France, Germany, and South Korea is a function of age and contribution durations. In various countries, such as Chile, Korea or the United States, PBD also increases during times of high unemployment. The generosity of PBD varies considerably. For example, the maximum PBD for a 40 year old varies in OECD countries from the least generous, such as the US (when not in a recession) or Slovakia with 6 months each, to the most generous such as Sweden (35 months), Iceland (36 months) and Belgium (indefinite).

UI benefits are typically calculated as a percentage - the replacement rate - of preunemployment gross or net earnings, subject to a maximum benefit level. Replacement rates and maximum levels vary considerably across countries. Most countries feature replacement rates between 50 and 65 percent, though some are significantly more generous (such as Denmark with 90 percent, Luxembourg with 80 percent or the Netherlands with 75 percent). Furthermore, there are large differences in maximum benefit levels, ranging from 33 percent of the average wage in a country (Turkey) to 227 percent (France), with an average of 77 percent among OECD countries. The maximum benefit level can substantially reduce the mean replacement rate. For example, the United States offer a relatively high replacement rate of 53 percent, but benefits are capped at around 41 percent (varying by state) of the average wage level, making it effectively one of the less generous UI systems. While the majority of countries pay a constant benefit level up to the PBD, some UI systems feature a declining benefit path. Benefits in the Netherlands, for example, drop from a 75 percent replacement rate to a 70 percent replacement rate after 2 months. Similarly benefits in Sweden drop from 80 to 70 percent after 9 months and similar step-downs can be found in Hungary, Slovenia, Spain and Italy, among others. As discussed in Section 4.4, the effect and optimality of the path of UI benefits is an active area of research.

Most countries require workers to actively search for jobs while receiving UI benefits and monitor job search efforts in various ways (such as asking the recipient for documentation about job applications). If workers reject job offers deemed acceptable by the UI agency or fail to fulfill other search requirements, he or she may be sanctioned with benefit cuts. Furthermore, UI agencies often provide various forms of support to help job seekers find jobs or by providing them with additional training and education programs to acquire skills valued in the labor market. The prevalence of such programs, often labeled active labor market 
programs (ALMP) varies across countries, but may constitute a very important part of the services provided by the UI system. Discussing ALMP in depth is beyond the scope of this paper, but see for example Card et al. (2010) and Card et al. (2015c) for excellent surveys. Finally, some countries permit UI recipients to work part-time while continuing to receive partial or full benefits. These provisions are often viewed as a way to reduce the disincentive effect of UI and to encourage workers to take on part-time work as a stepping stone towards full-time employment.

UI is typically financed through employer contributions and payroll taxes paid by workers. In many countries the government supplements the UI funds from general tax revenue either regularly or during times of economic downturns. The contribution rates, as a percentage of gross earnings, vary between around 1 and 3 percent, are often split evenly between workers and employers.5 As discussed in Sections 4.2 and 4.6, to what extent the financing of UI is separate or integrated with overall budget considerations can make an important difference in calculating the welfare effects of UI.

\section{AN INTEGRATED MODEL OF OPTIMAL UI BENEFIT LEVELS AND DURATIONS}

Designing a UI system and choosing the various parameters such as benefit levels and durations involves finding the right balance between providing insurance to the unemployed without distorting incentives to work too much. In this section we develop a simple model of the optimal level and duration of unemployment benefits that formalizes this trade-off and identifies the empirical parameters to be estimated to analyze the welfare aspects of UI. The model is based on Baily (1978), Chetty (2008) and Schmieder et al. (2012a), but we integrate the treatment of UI benefit levels and benefit durations and derive comparable expressions for the welfare effects of UI. To achieve this, we simplify the exposition relative to these papers by assuming that individuals are hand-to-mouth consumers (i.e., there is no saving). Furthermore, we follow Chetty (2008) and assume workers face a fixed wage that is high enough to ensure that any job offer will be accepted and search effort is the only choice variable by individuals. This allows for a straightforward setup and an intuitive derivation of the main

\footnotetext{
${ }^{5}$ See Carter et al. (2013) Graph 3.
} 
results, even in a dynamic model. Below we briefly discuss how relaxing these assumptions affects the setup and results.

\subsection{The individual job search problem}

The model centers on a worker who becomes unemployed at time $t=0$. The model is set in continuous time and we assume that the horizon lasts until time $T$, when the individual retires. She chooses search effort $s_{t}$ at each point in time, which we normalize to the arrival rate of job offers. Since any job offer is accepted this also equals the exit rate from unemployment and therefore determines the survival probability $S_{t}$ of remaining in unemployment at time $t$, which is given as $S_{t}=\exp \left(-\int_{0}^{t} s_{t} d t\right)$. Search effort $s_{t}$ results in a search cost of $\psi_{t}\left(s_{t}\right)$, which we assume to be differentiable, increasing and convex.

While unemployed, the individual receives UI benefits $b_{t}$ and consumes $c_{u, t}=b_{t}+y_{u}$, where $y_{u}$ may be income from other sources such as home production. ${ }^{6}$ We assume that $y_{u}$ is exogenously given and constant throughout the unemployment spell. The corresponding flow utility is given as $u\left(c_{u, t}\right)$. Once she finds a job, the worker receives a fixed wage $w$ and has to pay taxes of $\tau$, thus resulting in consumption $c_{e}=w-\tau$. Her flow utility then becomes $v\left(c_{e}\right)$, where $v($.$) , like u($.$) , is assumed to be increasing and concave. Different flow utility functions$ in employment $v($.$) and unemployment u($.$) capture the possible effort cost of working or$ the valuation of leisure, as well as possible complementarities between leisure (working) and consumption. To simplify notation we assume that there is no discounting.

Lifetime expected utility of an individual is given as: $:^{7}$

$$
W=\int_{0}^{T}\left\{S_{t} u\left(c_{u, t}\right)+\left[1-S_{t}\right] v\left(c_{e}\right)-S_{t} \psi_{t}\left(s_{t}\right)\right\} d t
$$

This equation captures the basic trade-off in the individual's decision problem. Higher search effort results in a faster exit rate from unemployment (lower $S_{t}$, which improves utility given $v\left(c_{e}\right)>u\left(c_{u, t}\right)$ ), but also comes at a higher effort cost $\psi_{t}$.

\footnotetext{
${ }^{6} y_{t}$ may also represent support from spouses or family members or self insurance through savings. Allowing for such endogenous forms of consumption adjustments makes the model somewhat more complicated but provides very similar results.

${ }^{7}$ We obtain this simple expression for expected lifetime utility rather than having to rely on a recursive formulation as in Chetty (2008), Schmieder et al. (2012a) and others, because the utility while employed does not depend on when an individual finds a job.
} 


\subsection{The Social Planner's Problem}

Social welfare in this problem is the unemployed individual's expected lifetime utility. The social planner sets the UI benefit path in order to maximize social welfare, while taking into account that the unemployed individual will adjust their search effort in response to the path of UI benefits. Furthermore the social planner has to set the tax level $\tau$ to finance UI benefits. To simplify this problem further, we restrict the planner's choice set to benefit paths with constant benefit levels up to a finite time horizon $P$, so that $b_{t}=b$ for $t \leq P$ and $b_{t}=0$ for $t>P$. Consumption during unemployment is then $c_{u, t \leq P}=b+y_{u}$ for $t \leq P$ and $c_{u, t>P}=y_{u}$ for $t>P$. As we saw in the previous section, this corresponds to the structure of UI in most countries. Much of the policy debate (and actual reforms) are about the optimal level and duration of UI benefits in this setup. However as we will discuss below, the model can also be used to study more flexible benefit paths.

In the one-step UI system, equation (1) can be rewritten as:

$$
W=\int_{0}^{P} S_{t} u\left(c_{u, t \leq P}\right) d t+\int_{P}^{T} S_{t} u\left(c_{u, t>P}\right) d t+\int_{0}^{T}\left[1-S_{t}\right] v\left(c_{e}\right) d t-\int_{0}^{T} S_{t} \psi_{t}\left(s_{t}\right) d t,
$$

where the first term on the right hand side represents the expected utility while unemployed and receiving UI benefits, the second term the utility after benefits are expired, the third term the utility while employed and the last term the expected search cost.

The social planner has to satisfy the constraint that total tax revenue has to equal the amount of UI benefits paid out plus some level of exogenous per capita government spending $E$. Since the social planner can smooth over many individuals, this budget constraint only has to hold in expectation. If we denote the expected duration of receiving UI benefits as $B=\int_{0}^{P} S_{t} d t$ and the expected duration in unemployment as $D=\int_{0}^{T} S_{t} d t$, then we can write the budget constraint as:

$$
(T-D) \tau=B b+E
$$

The social planner maximizes equation (2) subject to the budget constraint (3) and to the condition that the individual chooses search behavior optimally. Individual behavior is a function of UI benefits and durations, so that we can write the tax implied by the budget 
constraint as a function of $b$ and $P: \tau(b, P)=\frac{B(b, P)}{T-D(b, P)} b+\frac{E}{T-D(b, P)} \mathrm{g}^{8}$ Plugging this into $W$ we can write the Social Planner's problem as an unconstrained problem:

$$
\max _{b, P} W(b, P, \tau(b, P))
$$

where search effort is determined by $b$ and $P$.

\subsection{Characterizing Optimal UI Levels and Durations}

The marginal effect of increasing the level of UI benefits is given as:

$$
\begin{aligned}
\frac{d W}{d b} & =\int_{0}^{P} S_{t} d t u^{\prime}\left(c_{u, t \leq P}\right)-\int_{0}^{T}\left[1-S_{t}\right] d t v^{\prime}\left(c_{e}\right) \frac{d \tau}{d b} \\
& =B u^{\prime}(b)-(T-D) v^{\prime} \frac{d \tau}{d b}
\end{aligned}
$$

where we use the fact that changes in $s_{t}$ (and therefore $S_{t}$ ) do not affect welfare at the margin due to the envelope theorem. Differentiating the budget constraint to get $\frac{d \tau}{d b}$, some rearranging and dividing both sides by the marginal utility of the employed we obtain:

$$
\begin{aligned}
& \frac{d W}{d b} \frac{1}{v^{\prime}\left(c_{e}\right)}=\underbrace{B}_{\text {Mechanical increase }} \times \underbrace{\frac{u^{\prime}\left(c_{u, t \leq P}\right)-v^{\prime}\left(c_{e}\right)}{v^{\prime}\left(c_{e}\right)}}-\underbrace{\left(\frac{d B}{d b} b+\frac{d D}{d b} \tau\right)} \\
& \text { in transfer } \\
& \text { Social Value } \\
& \text { Behavioral Cost } \\
& \text { of } \$ 1 \text { add. transfer } \\
& \text { Mechanical Transfer to Unemployed }
\end{aligned}
$$

The division by $v^{\prime}\left(c_{e}\right)$ represents a rescaling of the marginal welfare effect, such that the left hand side of this equation is the welfare effect of increasing UI benefit levels by one dollar in the unit of a one dollar increase in consumption of the employed. The equation has a simple interpretation: increasing UI benefits by $\$ 1$ increases the total transfers to the unemployed by 2 components: $B+\frac{d B}{d b} b$. The first represents the mechanical increase in the transfer, if behavior were unchanged, while the second represents the increase in the transfer due to

\footnotetext{
${ }^{8}$ The addition of $E$ is more than just for completeness - it exemplifies that if other government expenditures are financed by taxes on earnings, the required tax to balance the budget - and hence the budget costs of a reduction in nonemployment benefits - is higher. We show in Section 4.2.1 that this can make an important difference.
} 
changes in behavior. Individuals who change their their search effort in response to $d b$, do not experience a first order utility gain due to the envelope theorem (they were already optimizing with respect to search effort). Therefore, only the mechanical part of the transfer is valued by the social planner. This transfer of $B$ dollars is valued at the gap in marginal utilities between unemployed (who receive the transfer) and the employed (who pay for it). However, the transfer leads to distortions impacting the social planner's budget: on the one hand the behavioral increase in the transfer $\left(\frac{d B}{d b}\right)$ and on the other hand the decline in tax revenue due to the increase in nonemployment durations $\frac{d D}{d b}$.

Notice that the behavioral cost (i.e., the marginal effect of UI benefits on nonemployment durations and UI durations) is not enough to gauge whether the distortion coming from UI is large relative to the benefit of increasing UI benefits by $\$ 1$. It is crucial to also take into account how much more is actually transferred to the unemployed, which is $B$ dollars. A convenient normalization is therefore to divide equation (6) by $B$, so that it expresses the marginal effect on welfare of increasing the transfers to the unemployed by $\$ 1$ :

$$
\begin{aligned}
& \frac{d W}{d b} \frac{1}{B v^{\prime}\left(c_{e}\right)}=\underbrace{\frac{u^{\prime}\left(c_{u, t \leq P}\right)-v^{\prime}\left(c_{e}\right)}{v^{\prime}\left(c_{e}\right)}}-\underbrace{\left(\eta_{B, b}+\eta_{D, b} \frac{D}{B} \frac{\tau}{b}\right)} \\
& \text { Social Value Behavioral Cost } \\
& \text { of } \$ 1 \text { add. transfer per } \$ 1 \text { add. Transfer }
\end{aligned}
$$

where $\eta_{B, b}=\frac{d B}{d b} \frac{b}{B}$ and $\eta_{D, b}=\frac{d D}{d b} \frac{b}{D}$ are the elasticities of the duration of receiving UI benefits and the unemployment duration with respect to the monthly benefit level. The first term on the right represents the social value of increasing the transfer by $\$ 1$ which depends on the gap between the marginal utility of benefit recipients relative to the marginal utility of the employed. The second term on the right represents behavioral cost of increasing the transfer by $\$ 1$ to the government budget.

If we let $\widetilde{u}^{\prime}\left(c_{u, t>P}\right) \equiv \frac{1}{b} \int_{y_{u}}^{y_{u}+b} u^{\prime}(c) d c$ be the average marginal utility for an individual between consumption levels of $y_{u}$ and $y_{u}+b$, then we can write the marginal effect of increasing transfers by $\$ 1$ through a PBD extension on welfare as: 


$$
\begin{aligned}
& \frac{d W}{d P} \frac{1}{S_{P} b v^{\prime}\left(c_{e}\right)}=\underbrace{\frac{\tilde{u}^{\prime}\left(c_{u, t>P}\right)-v^{\prime}\left(c_{e}\right)}{v^{\prime}\left(c_{e}\right)}}-\underbrace{\frac{1}{S_{P}}\left(\int_{0}^{P} \frac{d S_{t}}{d P} d t+\frac{d D}{d P} \frac{\tau}{b}\right)} \\
& \text { Social Value Behavioral Cost } \\
& \text { of } \$ 1 \text { add. transfer per } \$ 1 \text { add. Transfer }
\end{aligned}
$$

The structure of this equation follows closely equation (7). The first term on the right represents the social value of increasing the mechanical transfer by $\$ 1$, where a subtle difference is that the gap in marginal utilities now depends on the (average) marginal utility of an exhaustee. Note that due to the convexity of $u($.$) , we have that \widetilde{u}^{\prime}\left(c_{u, t>P}\right)>u^{\prime}\left(c_{u, t \leq P}\right)$ and the social value term will be larger in equation (8) than in equation (7).

The second term represents the behavioral cost, where $\int_{0}^{P} \frac{d S_{t}}{d P} d t$ is the increase in benefit duration $B$ that is due to the disincentive effect of increasing $P$, which increases government spending at a rate of $b$ dollars. $\frac{d D}{d P}$ captures the increase in nonemployment which reduces tax revenue by $\tau$ dollars per time unit. This increase in spending per increase in potential benefit duration $P$ is divided by the additional transfer that is associated with it, which is equal to $S_{P} b$ since each exhaustee $S_{P}$ receives $b$ dollars per additional month of PBD.

Equation (7) is well known as the Baily-Chetty formula, which has been used in many contexts to describe the trade-offs around the optimal UI generosity level. A version of equation (8) was first derived in Schmieder et al. (2012a).

Implications. An attractive feature of the integrated treatment of benefit levels and durations in equations (7) and (8) is that the behavioral cost is expressed in the same units and is directly comparable. For example, if $\eta_{B, b}+\eta_{D, b} \frac{D}{B} \frac{\tau}{b}>\frac{1}{S_{P}}\left(\int_{0}^{P} \frac{d S_{t}}{d P} d t+\frac{d D}{d P} \frac{\tau}{b}\right)$, this implies that increasing transfers to the unemployed via benefit increases come at a larger budgetary cost than increasing transfers via a benefit extension. If this inequality holds, this would suggest that extending benefits is preferable to increasing them, since exhaustees are likely to have larger marginal utility of consumption than UI recipients.

The equations also highlight differences in the effects of changes to benefit levels and durations. For example, in the absence of a behavioral response $\left(\eta_{D, b}=\eta_{B, b}=0\right)$, equation (7) would imply that marginal utility of the employed and unemployed should be equalized, which in a situation where both have the same utility functions would imply that $c_{u, t \leq P}=c_{e}$. Similarly, Equation (8) implies that in the absence of a behavioral effect UI benefits should 
be paid indefinitely.

Many papers in the literature have studied the disincentive effects of UI benefits and typically report estimates of the marginal effect, or elasticity, of changes in $b$ or $P$, on unemployment durations $(D)$ or UI benefit durations $(B)$. However, equations (8) and (7) show how given different levels of $B$ or $S_{P}$, a given increase in $b$ (or $P$ ) may represent a very different increase in transfers. Furthermore, whether behavioral responses are costly to the government depends crucially on the benefit and tax levels. When contrasting estimates of the disincentive effects across studies, it is therefore more informative to compare the disincentive effect rescaled to the behavioral cost per $\$ 1$ transfer. In Section 4.2 , we calculate this rescaled disincentive effect for a range of recent empirical studies of UI parameters on labor supply $9^{9}$

\section{APPLICATIONS AND EXTENSIONS OF THE BAILY-CHETTY FORMULA}

A long literature in labor economics and public finance has estimated the effect of UI benefit parameters on employment and unemployment outcomes. In this section we summarize the results from recent studies that have have improved the measurement and identification of the labor supply effects of UI (subsection 4.1) and how these estimates can be interpreted and made comparable in the light of our theoretical framework (4.2). The remainder of the section discusses various extensions of this framework in recent papers.

\subsection{Recent Estimates of Labor Supply Effects of UI Benefits}

Identification. UI benefits and employment outcomes are frequently jointly related to individual earnings, employment histories and conditions in the aggregate labor market. As a result, simple OLS regressions are unlikely to recover the true labor supply effects of UI benefits. To address this identification problem, most studies seek to exploit changes in UI parameters unrelated to labor market conditions and individuals' own characteristics.

\footnotetext{
${ }^{9}$ The above model is stylized, but the basic formulas are remarkably robust to altering the baseline assumptions. For example, it is robust to allowing for stochastic wage offers with a reservation wage decision since possible wage effects of the UI benefit path through reservation wages are already internalized by the individual and do not affect the welfare calculation due to the envelope theorem. Similarly, it is conceptually straightforward to allow for endogenous savings, where the unemployed use savings to smooth consumption. (see Chetty, 2008, Schmieder et al., 2012a). It is however straightforward to generalize to a situation with many heterogeneous unemployed with different labor supply responses to UI. If the social planner is not constrained to a single UI benefit path, then the optimal policy would be to set different UI levels for different groups or at different points in time, something we will return to in the Section 4.3.
} 
In the United States, several studies have analyzed policy-driven variation in both UI benefit levels and UI benefit durations. Most variation in UI benefit durations is at the state level, and arises from the Extended Benefit (EB) and the Emergency Unemployment Compensation (EUC) programs (see, e.g., Rothstein, 2011). Both programs usually raise UI durations, and sometimes benefit levels, in response to local and national unemployment conditions 10 To convincingly use this variation it is paramount to sufficiently control for labor market conditions in a state, and most studies attempt to do this. There also have been politically motivated changes in UI benefit durations and levels at the state level, independent of economic conditions, which have provided useful case studies.

Another approach to estimating the effect of UI benefits has been to exploit discontinuities in the benefit schedules or benefit durations that are independent of labor market conditions. In particular, many European UI systems feature discrete changes in the duration of UI benefits by age (e.g., Germany, Austria, Italy, Portugal) or job tenure (e.g., Austria). In the U.S. and Austria, discontinuities in the marginal benefit schedules have been used to identify the effect of changes in UI benefit levels. These institutional features provide sharp exogenous variation in the duration or level of UI benefits in so far as individuals do not anticipate the policy or manipulate their UI application dates or earnings levels. Papers studying such variation in the context of a regression discontinuity or regression kink design assess this potential bias in detail (e.g. Card et al., 2007a; Schmieder et al., 2012a. b; Landais, 2015, Card et al., 2015b). In some cases, exogenous reforms can be used to confirm the finding from the cross-sectional analysis (e.g., Schmieder et al., 2012a).

Measurement. Data is another important challenge when studying the effect of UI benefits. Section 3 highlights that the key outcomes to measure the welfare effects of UI are total nonemployment duration, as well as duration and amounts of UI benefit receipt. In the U.S. no large data source measuring nonemployment spells, i.e., the duration between jobs, is currently available. Hence, studies have either used measures of self-reported unemployment

\footnotetext{
${ }^{10}$ The EB program is based on state-specific triggers, and raises UI duration for states whose unemployment rate exceeds a certain thresholds. The EB program is entirely managed by the states, and hence states differ in the amount of the increase as well as the trigger thresholds. The EB has diminished in importance over time (see, e.g., Figure 2 of Congressional Budget Office (2004)). The EUC is a federal program enacted by U.S. Congress, and increases the maximum UI benefit duration for all states. When an EUC program is active, states experience increases in UI durations if their unemployment rates exceed a common threshold value. In some cases, states or Congress also raise UI benefit levels in response to labor market conditions.
} 
duration in the Current Population Survey (CPS), or duration of UI benefit receipt from administrative records. Since many unemployed individuals exhaust UI benefits before finding a job, the CPS-based measure is in principle preferable. However, the CPS measure is noisy and does not capture worker's total length of nonemployment, which may include periods in which workers do not declare themselves unemployed. While the administrative data from the UI system has information on quarterly earnings, and hence could be used to study nonemployment durations, this is quite coarse. Some U.S. studies based on administrative data focused on UI benefit duration and the spike at benefit exhaustion as main outcomes. However, while duration of UI benefits, and in particular the UI exhaustion rate, are indeed key components in the welfare evaluation of UI benefit extensions neither captures the employment effects of UI parameters, since the majority of workers do not return to work immediately after benefit exhaustion (e.g., Card et al. (2007b) and Schmieder et al. (2012a)).

Many recent European studies make use of spell-based administrative data, which allow researchers to measure the duration of UI benefit receipt and nonemployment, as well as the incidence of benefit exhaustion. However, the nature of the data does not allow measuring unemployment as defined in labor force surveys, since information on individuals' job search activity is usually not available. The use of nonemployment instead of unemployment has benefits and disadvantages. It is well known that whether individuals self-declare as unemployed in surveys varies with the institutional and economic environment. Moreover, it is recognized that many of those typically not categorized as unemployed are really partially attached to the labor market. Nonemployment duration has the advantage that it captures all types of nonemployment that might respond to UI benefits. Yet, in some cases it is meaningful to explicitly distinguish between unemployment and non-participation. For example, UI benefits may raise unemployment by increasing participation rather than lowering employment. Rothstein (2011) shows that this can be relevant and that UI extensions helped to prevent labor force exit in the US in the Great Recession.

Findings on Benefit Durations. Several classic studies measured the effect of UI benefit parameters during the 1970s and 1980s (e.g. Meyer, 1990, Katz and Meyer, 1990; Meyer, 1995). Since these are covered in surveys by Krueger and Meyer (2002) and Meyer (2002), we will focus on more recent work. Several recent studies have evaluated the effect of the increases in UI benefit duration during the Great Recession using survey data and state- 
time variation in UI benefits(e.g. Rothstein, 2011; Valletta, 2014, Farber and Valletta, 2015; Kroft and Notowidigdo, 2016). This work has received substantial attention because of the unprecedented rise in UI durations to a potential maximum of 99 weeks (in contrast, during the 1982 recession, which had similar rates of unemployment as the Great Recession, maximum potential benefit duration increased to 52 weeks). Although the magnitude of the findings are not immediately comparable between studies due to differences in methodology, the overall finding of this later round of studies suggested that there was a significantly negative but moderate effect of UI benefit increases during the Great Recession on unemployment duration. Compared to earlier studies, the estimated labor supply effects of UI durations in the Great Recession tended to be smaller, raising the question whether labor supply responses to UI benefit had a cyclical component. We return to this in Section 4.3. Based on these findings alone, the conclusion was that UI could not fully explain the rise in unemployment rates or mean unemployment duration (e.g., Rothstein, 2011; Aaronson et al., 2010). An important caveat is that by focusing on labor supply responses of the unemployed themselves, these studies do not address potential aggregate effects of UI extensions, something that we discuss Section 4.6 .

Despite the care taken in most studies to control for differences in labor market characteristics between treatment and control groups, the fact that the main source of variation in UI benefit duration arises from labor market conditions makes it difficult to fully rule out that these estimates partly capture the effect of weak economic conditions. Hence, studies chiefly relying on this source of variation in UI benefits may overstate the effect of UI durations on reemployment probabilities, as suggested in Card and Levine (2000), who examine a purely politically motivated policy change. They find UI benefit elasticities that are smaller than those estimated based on variation from the U.S. Extended Benefits (EB) and Emergency Unemployment Compensation (EUC) programs used in the earlier studies. More recently, some states have cut UI benefits, partly due to budgetary pressures. While the financial situation of a state's UI system is not exogenous to recent labor market conditions, these cuts were also partly politically motivated, and hence may provide useful variation (e.g., Johnston and Mas, 2015).

Studies from Europe also point to moderate labor supply effects from UI benefit durations. While most recent studies in the U.S. have analyzed the response in hazard rates, most 
European studies have studied nonemployment duration and hence can be easily summarized using duration elasticities. These marginal effects $\left(\frac{d D}{d P}\right)$ and elasticities $\left(\frac{d D}{d P} \frac{P}{D}\right)$ for a selective set of studies of European studies are shown in Panel A of Table 1. The median of the estimated marginal effects is 0.13 , implying that for a one-month increase in UI durations, nonemployment durations rise by about 4 days. Excluding two outliers at the top and bottom, respectively, the mean marginal effect is 0.23 , with a range from 0.05 to 0.65 . Given both nonemployment durations (D) and potential benefit durations (P) vary substantially across countries, the next column shows the duration elasticity. The median elasticity is 0.37 (after dropping the highest and lowest value, the mean is 0.41 and the range is from 0.1 to 1 ). Not surprisingly, the range of variation is smaller in the U.S. for the limited studies for which duration elasticities were available, shown in Panel B of Table 1. There, elasticities ranged from 0.1 (Card and Levine, 2000) to 0.41 (Katz and Meyer, 1990), but were in the similar ball park as estimates from Europe.

Despite some expected variation, the labor supply estimates in Table 1 show a reasonable degree of congruence between countries and studies. Yet, as we discuss further in Section 4.2.1, care has to be taken to interpret these estimates. First, as with any uncompensated labor supply elasticity, the total labor supply response to a change in UI benefits combines both a substitution ('moral hazard') effect and an income ('liquidity') effect. Second, as discussed in Section 3, the full efficiency cost of UI depends on additional parameters that are likely to vary across studies. We discuss this in Section 4.2.

There a several other reasons for caution in directly comparing the estimates in Table 1. One issue is that the definition of unemployment duration differs; while most European studies study the duration between jobs, most US studies measure the duration of unemployment (if using survey data) or the duration of UI receipt (if using administrative). Another issue relates to the presence of more generous social insurance support after UI exhaustion. The benefits available after UI exhaustion affect the size of the implied labor supply elasticity 11 In addition, these estimates pertain to different samples, different nonemployment durations, and different benefit extensions. As it is likely that labor supply responses are heterogeneous

\footnotetext{
${ }^{11}$ Schmieder et al. (2012a) try to address this issue, and report that for a population unlikely to take up second tier benefits, the implied labor supply effects are comparable in magnitude to those of the US. Yet we are not aware of a more formal analysis of the how the presence of social insurance after UI exhaustion, or of other UI parameters such as benefit levels, modify the main impact of UI benefits on labor supply.
} 
along all of these dimensions, different estimates capture mean responses for different groups and experiments. Providing a more systematic picture of the effect of UI benefit levels and durations will be a useful avenue for future research.

Findings on Benefit Levels. To a lesser degree, UI benefit levels have differed between states and varied over the business cycle in the U.S., and this variation has been used to estimate their effect on labor supply (e.g., Moffitt 1985; Katz and Meyer 1990; Chetty 2008; Kroft and Notowidigdo, 2016). Solon (1985) and Meyer and Mok (2007) analyze state-level benefit changes unrelated to business cycle conditions. Moving beyond traditional cross-state, cross-time designs, several recent studies have exploited kinks in the benefit schedules to provide experimental estimates of the UI benefit effect (e.g., Card et al., 2015b a; Landais, 2015). Table 2 summarizes estimates from 18 studies from 5 different countries, of which 11 estimates are from the U.S. The duration elasticities vary from 0.1 to 2 , with a median of 0.53. For the U.S. alone, the median is 0.38 , and the range is from 0.1 and 1.2 in the US, with all but two estimates lying below 0.7 . Overall, the elasticities with respect to UI benefit levels are somewhat higher than the elasticities with respect to PBD. This might arise from the fact that the response to benefit changes is more evenly distributed throughout the spell compared to the response to durations, whose effect is mitigated by discounting and which over-proportionally affects workers exhausting benefits.

\subsection{The Welfare Effects of Changes in UI Benefits}

\subsubsection{The Behavioral Cost of UI Benefit Changes}

The importance of estimating the labor supply effect goes beyond the traditional analysis of labor supply behavior. As discussed in equations (7) and (8) in Section 3, the labor supply responses to changes in UI benefits and durations are key inputs in assessing the efficiency costs of UI benefits. A clear message from the empirical findings discussed in Section 4.1 is that UI induces efficiency costs by reducing labor supply and hence tax revenues. However, as discussed in Section 3, labor supply elasticities alone do not capture the full disincentive effect of UI benefits. In the remainder of this section, we will derive more comparable measures of the efficiency costs of UI.

The theory discussed in Section 3 provides expressions of the efficiency costs per additional 
dollar of UI benefits that can in principle be directly calculated from the data. One difficulty in implementing the formulas in equations (7) and (8) for existing studies is that most publications do not report direct estimates of some or most of the required components. To be nevertheless able to infer about the efficiency cost of UI benefits implied by previous research, we derived an approximate welfare formula for the case in which the hazard of exiting the unemployment spell is constant (see Schmieder et al., 2012a for details). If the exit hazard from unemployment $s$ is constant over time (but potentially changing with different levels of $P)$, then we can write $\frac{d B}{d b}=\frac{d D}{d b} \xi$ and $\int_{0}^{P} \frac{d S_{t}}{d P} d t=\frac{d D}{d P} \xi$, where $\xi \equiv 1-(1+P s) e^{-P s} \sqrt[12]{ }$ For this case equations (7) and (8) simplify to convenient expressions of the efficiency cost that can be calculated based on information available in most studies.

The resulting first order condition for the marginal welfare effect of a change in the UI benefit level is:

$$
\begin{aligned}
\frac{d W}{d b} \frac{1}{B v^{\prime}\left(c_{e}\right)}=\underbrace{\frac{u^{\prime}\left(c_{u, t \leq P}\right)-v^{\prime}\left(c_{e}\right)}{v^{\prime}\left(c_{e}\right)}}_{\begin{array}{c}
\text { Social Value } \\
\text { of } \$ 1 \text { add. transfer }
\end{array}}-\underbrace{\eta_{D, b} \frac{1}{1-S_{P}}\left(\xi+\frac{\tau}{b}\right)}_{\text {Behavioral Cost }},
\end{aligned}
$$

where $\eta_{D, b}=\frac{d D}{d b} \frac{b}{D}$ is the elasticity of nonemployment duration with respect to benefits and $S_{P}$ is the UI exhaustion rate. Similarly we can derive the marginal effect on welfare of an increase in potential benefit duration (PBD) (see Web Appendix):

$$
\begin{aligned}
\frac{d W}{d P} \frac{1}{S_{P} b v^{\prime}\left(c_{e}\right)}= & \underbrace{\frac{\widetilde{u}^{\prime}\left(c_{u, t>P}\right)-v^{\prime}\left(c_{e}\right)}{\text { of } \$ 1 \text { add. transfer }} \quad}_{\begin{array}{c}
\text { Social Value } \\
v^{\prime}\left(c_{e}\right)
\end{array}}-\underbrace{\frac{d D}{d P} \frac{1}{S_{P}}\left(\xi+\frac{\tau}{b}\right)}_{\begin{array}{c}
\text { Behavioral Cost } \\
\text { per } \$ 1 \text { add. Transfer }
\end{array}}
\end{aligned}
$$

Note that as before, these expressions measure the consumption value of the marginal welfare effect in units of the total (mechanical) transfer of UI benefits before the behavioral adjustment (which is $B$ for benefit levels, and $S_{P} b$ for benefit durations). A key advantage of the two new behavioral cost terms in equations $(9)$ and 10 is that they can be directly

\footnotetext{
${ }^{12}$ The effect of a benefit increase on the duration of receiving UI benefits and on unemployment duration are closely related because $\frac{d B}{d b}=\int_{0}^{P} \frac{d S_{t}}{d b} d t$ and $\frac{d D}{d b}=\int_{0}^{T} \frac{d S_{t}}{d b} d t$.
} 
compared to each other.

The marginal welfare effects in the form of equations (9) and 10 highlight that the most commonly reported parameters - the elasticity of unemployment durations with respect to the benefit level $\eta_{D, b}$ and the marginal effect of increasing PBD on unemployment durations $\frac{d D}{d P}$ - are not sufficient to gauge the magnitude of the disincentive effect. It also shows that the elasticity of unemployment durations with respect to $\mathrm{PBD}, \eta_{D, P}$, does not enter the marginal welfare formula without some rescaling.

The final two columns of Table 1 and 2 report estimates of the behavioral cost of a marginal increase of UI benefit durations and levels estimated for different studies based on the second term in equations (9) and (10), respectively. We have to infer the hazard rate $s$, the term $\xi$, and the exhaustion rate $S_{P}$ from statistics on mean nonemployment and benefit duration reported in the papers.

To get a value for $\frac{\tau}{b}$, let $\hat{\tau}$ be the tax rate, so that $\tau=\hat{\tau} w$ and $\rho$ the UI replacement rate, so that $b=\rho w$, as long as pre- and post-unemployment wages are approximately equal ${ }^{13}$ We therefore use $\frac{\hat{\tau}}{\rho}=\frac{\tau}{b}$ to calculate the behavioral cost. To obtain a value for $\rho$, we use the statutory replacement rates for each country (OECD, 2015). The tables present estimates of the efficiency cost for two values of $\hat{\tau}$, that correspond to two assumptions about the integration of the UI system with the general government budget. The next-to-last column shows efficiency cost estimates using an average of the worker contribution rate (e.g., payroll taxes) to the UI system across countries. This corresponds to typical applications of the BailyChetty formula, which only takes into account the budget shortfall from longer nonemployment durations for the UI system. As noted by Lawson (2014) and Nekoei and Weber (2015), this is likely to understate the budget shortfall in practice, since workers pay additional taxes on earnings to finance other government expenditures. Therefore, the final column of Table 1 shows estimates of the efficiency cost using an estimate of the average tax wedge on labor ${ }^{14}$

Consider first the estimates of the efficiency cost of benefit durations shown in the last two columns Table 1. Using the UI tax rate and excluding three extreme outlier values, the

\footnotetext{
${ }^{13}$ Alternatively one could scale this by the average wage loss after unemployment.

${ }^{14}$ This is captured in the model of Section 3 by adding an additional government expenditure $E$ to the budget constraint in equation (3). We use a common value for all countries for the UI tax rate comes from Carter et al. (2013), commissioned by the International Labor Organization. We use country-specific estimates of the tax wedge from the OECD (2015). ,
} 
behavioral cost for each additional $\$ 1$ transfer of UI benefits varies between $\$ 0.11$ and $\$ 2.13$, with a median of $\$ 0.6{ }^{15}$ The median value implies that for every dollar of (mechanical) transfer to existing UI beneficiaries, 1.6 dollars have to be raised: one dollar to finance the transfer (the mechanical cost) and 60 cents because of the loss of tax revenue due to the behavioral response (the behavioral cost). As expected, using the tax wedge instead to measure the effect on the government budget raises the efficiency costs. Excluding the same extreme outliers, these now range from $\$ 0.37$ and $\$ 4.58$, with a median of $\$ 1.78$. That is, for each dollar of UI transfer, about three dollars have to be raised. Estimates for the efficiency cost of benefit levels are shown in Table 2 and are generally lower than the effect of benefit durations. The median is $\$ 0.35$ (\$0.81) for $\hat{\tau}=\mathrm{UI} \operatorname{tax}(\hat{\tau}=$ tax wedge). This may be surprising, since the discussion in Section 4.1 (and the evidence in Tables 1 and 2) suggests that the labor supply effects of benefit levels are somewhat larger than that for levels. Looking at the formulas, the difference in efficiency costs arises because the labor supply effect is scaled by $1 / S_{P}$ for benefit durations instead of $1 /\left(1-S_{P}\right)$ for benefit levels, whose median values are approximately 5 and 1.25 for the studies in Table 1 . The intuition is that our formula gives the efficiency cost per unit of mechanical transfer. For example, in the case of UI durations, if there are few exhaustees (i.e., $S_{P}$ is low) the budget shortfall is distributed over a smaller group of people, and hence the cost per unit of transfer is large.

Overall, Tables 1 and 2 confirm the implication from labor supply estimates discussed in Section 4.1 that the efficiency costs can be substantial. However, they also imply that labor supply elasticities only imperfectly captures the actual variation in the efficiency costs shown in the tables. It is clear that while the marginal effect $\left(\frac{d D}{d P}\right)$ and the behavioral cost are positively correlated, the marginal effect does not fully capture the variation in behavioral cost. Excluding again three outliers in Table 1 , the $R^{2}$ of a simple descriptive linear regression of the true efficiency cost of an increase in UI benefit durations on the duration elasticity is $61-68 \%$. The average scaling factor $\left((\xi+\tau / b) / S_{P}\right)$ across studies as measured by the slope coefficient of regression is $-1.85(-4)$ when $\tau=\mathrm{UI} \operatorname{tax}(\tau=\operatorname{tax}$ wedge). Finally, not surprisingly, the

\footnotetext{
${ }^{15}$ The outliers are two values for Austria with efficiency costs above $\$ 50$, and the one negative efficiency cost. The Austrian outliers are from a sample of relatively old individuals where the UI expansion seems to have induced many workers to effectively drop out of the labor force until early retirement. Another reason for the large computed efficiency cost may be that the constant hazard approximation is particularly poor here, since it implies an exhaustion rate very close to zero, thus blowing up the efficiency cost.
} 
behavioral cost exhibits greater variance across studies than the labor supply elasticity, which ranges from -0.1 to -1 . Given how we implemented the formulas in equations (9) and (10), this is mainly due to variation in exhaustion rates $\left(S_{P}\right)$ and exit hazards $(s)$.

Overall, the exercise demonstrates that a more complete accounting of the behavioral costs requires not only labor supply estimates, but also also information on exhaustion rates, hazard rates, as well as parameters of the UI system such as benefit levels and tax rates. For a better understanding of the welfare effect of UI it would be useful if future studies reported a sufficiently extended set of statistics, which are easy to calculate from typical data used to anlayzed the employment effects of UI, to allow comparable calculations of the behavioral cost of UI benefits.

\subsubsection{The Marginal Social Value of UI Benefit Changes}

To use the framework discussed in Section 3 to assess the overall welfare effect of a change in UI benefits - and hence the optimality of UI benefits, one needs estimates of the social value of UI benefit extensions as well. That UI benefits have potentially large welfare benefits is already suggested by estimates of the labor supply effects. While the traditionally the labor supply elasticities of UI have been interpreted as substitution ('moral hazard') effects, if individuals are liquidity constrained, these estimates capture both substitution and income effects of UI benefits. Chetty (2008) estimates that more than half of the UI benefit labor supply elasticity in his sample of U.S. workers is due to a liquidity effect. This implies that a substantial fraction of the population is liquidity constrained, and hence benefits from more generous UI benefits.

If one were to use equations $(9)$ and $(10)$ to calculate the net welfare effect of a marginal change in UI benefits, it is necessary to recover the gap in marginal utilities. The literature has developed various approaches to this difficult question. Gruber (1997) observed that if the utility function is the same in unemployment and employment $v()=.u($.$) , then the gap in$ marginal utilities can be written as: $\gamma \frac{\Delta c_{1}}{c_{e}}$ where $\gamma$ is the coefficient of relative risk aversion and $\Delta c_{1}=c_{e}-c_{u, t \leq P}$ is the difference in consumption between the employed and the UI recipients. To obtain a measure of the gap in marginal utilities Gruber $(1997)$ estimated $\frac{\Delta c_{1}}{c_{e}}(b)=\alpha+\beta b$ and combined these estimates with typical values for $\gamma$ from the literature. More recently Kroft and Notowidigdo (2016) use the same approach to estimate how $\frac{\Delta c_{1}}{c_{e}}(b)$ (and therefore 
the gap in marginal utilities) varies by the state of the business cycle. Since assets have been shown to deplete throughout the unemployment spell, the social value of a benefit extension is likely to be higher. No current study estimates the social value for workers exhausting their UI benefits. However, several studies have analyzed the change in household income upon UI exhaustion (e.g. Rothstein and Valletta 2014, Congressional Budget Office 2004, Ganong and Noel, 2015). Under the assumption that absent UI benefits the decline in consumption is similar to the reduction in household income, one can again use Gruber (1997)'s approach to estimate the social value.

A second approach in the literature has been to directly infer the gap in marginal utilities from search effort responses to changes in incentives. Chetty (2008) showed that in a model with assets and endogenous savings, the gap in marginal utilities can be written as: $\frac{u^{\prime}\left(c_{u, t \leq P}\right)-v^{\prime}\left(c_{e}\right)}{v^{\prime}\left(c_{e}\right)}=\frac{-\partial s / \partial A}{\partial s / \partial A-\partial s / \partial b}$, where $\partial s / \partial A$ is the marginal effect of a one dollar increase in assets at the beginning of unemployment on search effort and $\partial s / \partial b$ is the marginal effect of increasing UI benefits by one dollar on search effort. This formulation highlights that the gap in marginal utilities corresponds to the ratio between the liquidity effect and the substitution effect of UI benefits. Furthermore, it has the advantage that it can be estimated using observed responses to changes in assets and UI benefits, which Chetty (2008) does using variation in UI benefits and severance payments.16

Panel A of Table 3 displays various estimates of the consumption decline at unemployment. In the U.S., these range from $6-15 \%$ in expansions to up to $20-27 \%$ in recessions. In terms of consumption changes at UI benefit exhaustion, using the Survey of Income and Program Participation Rothstein and Valletta (2014) report that at exhaustion household income drops to $0.6-0.7$ of pre-job loss income. The welfare gain of a $\$ 1$ of additional UI benefits implied by these numbers depends substantially on the chosen value of relative risk aversion. For a value of $\gamma=2$, the welfare gain implied by the numbers in Table 3 would range from $\$ 0.2$ in expansions and $\$ 0.4-0.5$ in expansions. For a value of $\gamma=5$, the welfare gains would range

\footnotetext{
${ }^{16} \mathrm{~A}$ third approach to empirically obtain the gap in marginal utilities was developed by Shimer and Werning (2007) in a model with stochastic wage offers where individuals search is characterized by a reservation wage. Shimer and Werning note that in such a model the reservation wage net of taxes is equal to the value of unemployment. Therefore, the marginal effect on welfare can be expressed as a function of the marginal effect of UI benefits on the reservation wage and of the disincentive effect of UI benefits. Estimates of changes in reservation wages are rare (see, e.g., Feldstein and Poterba (1984) or Krueger and Mueller (2016)). For a more detailed discussion of this approach see Shimer and Werning (2007) as well as Chetty (2009) who compares the different approaches to estimate the marginal utility gap.
} 
from $\$ 0.5$ to $\$ 1-1.25$.

Panel B of Table 3 shows three estimates of the welfare gain based on the ratio of moral hazard and liquidity effects. These tend to be larger than the values implied by the consumptionbased approach. As Chetty (2008) points out, the reason is in part that the liquidity effects he estimates are only compatible with high levels of risk aversion, such as $\gamma=5$. The advantage of the sufficient statistics approach is that one need not assume a value for $\gamma$, allowing one to implicitly infer on the degree of risk aversion from the data. Based on these results, a higher value of $\gamma$ to scale the consumption estimates in Panel A is likely to be more appropriate.

Overall, it is clear that the welfare gain of a marginal increase in UI benefits is positive and likely to be substantial, especially in recessions. However, the two approaches tend to give somewhat disparate results, with the higher estimates given by the relatively newer studies using liquidity effects. As these require fewer assumptions on risk aversion, generating additional estimates to corroborate existing findings is an important avenue for future research. This is particularly important since for smaller levels of risk aversion the net welfare effect of extensions in UI benefit generosity may as well be negative, especially for larger tax rates.

There are other important additional avenues for future research. Most papers that have implemented the sufficient statistics approach to derive the marginal welfare benefit of UI increases have focused on the effect of changing benefit levels. Therefore attempts to recover the gap in marginal utilities have been limited to estimating $\frac{u^{\prime}\left(c_{u, t \leq P}\right)-v^{\prime}\left(c_{e}\right)}{v^{\prime}\left(c_{e}\right)}$. However, in principle it should be straightforward to use very similar approaches to recover the gap in marginal utilities in consumption for the UI exhaustees: $\frac{\widetilde{u}^{\prime}\left(c_{u, t>P}\right)-v^{\prime}\left(c_{e}\right)}{v^{\prime}\left(c_{e}\right)}$. Since a large part of the policy debate focuses on the duration of benefits $P$ as opposed to benefit levels, this would be a promising area for future empirical research.

Once one has estimates of the components of equations (7) and/or (8), one can calculate the marginal effect of increasing benefits or durations in the current economy. Chetty (2008) and Shimer and Werning (2007) for example provide calculations that suggest there would be sizable increases in social welfare associated with increasing the level of UI benefits in the United States. In contrast, to determine the optimal level $b^{*}$ or duration $P^{*}$ of benefits, one could set the first order conditions equal to zero: $\frac{d W}{d b}\left(b^{*}\right)=0$ and $\frac{d W}{d P}\left(P^{*}\right)=0$. Solving the first order conditions for $b^{*}$ or $P^{*}$, however, requires specifying how the values of the sufficient statistics vary for values of $b$ and $P$ that are different then the ones in the current economy. 
Solving this problem is an important avenue for future research (see, e.g., Kolsrud et al., 2015) 17

\subsection{Should UI vary with Labor Market or Individual Characteristics?}

A recurring question is whether UI durations should be increased in recessions, and by how much; whether they should vary for different demographic groups in the population; or whether they should vary over the unemployment spell. The theory discussed in Section 3 implies that the optimal duration of UI benefits varies over time or in the population if either the insurance benefit or the efficiency cost varies. For example, as shown in equation (10) for the case of UI benefit durations, two key sources of variation that are easily measured in the data are the UI exhaustion rate and the labor supply elasticity. Hence, several studies have assessed the heterogeneity in these parameters along various dimensions.

For example, Schmieder et al. (2012a) and Kroft and Notowidigdo (2016) assess whether UI durations and benefits, respectively, should vary over the business cycle. Since job search theory does not provide a clear indication as to which direction the labor supply elasticity should change in recessions, the question becomes an empirical one. Schmieder et al. (2012a) find that in Germany, over 30 years, the UI exhaustion rates increased substantially in recessions. They show that the labor supply effect as commonly estimated $(d D / d P)$ is acyclical. They also calculate the adjusted marginal effect per beneficiary $\left(\frac{d D}{d P} \frac{1}{S_{P}}\right)$, which prominently figures in the true behavioral cost in equation (10). Since the exhaustion rate is highly cyclical in Germany and in other countries (e.g., Congressional Budget Office 2004), the adjusted marginal effect is strongly countercyclical. Absent substantial changes in utility parameters, this implies that the behavioral cost in equation (10) is countercyclical and that as a result UI

\footnotetext{
${ }^{17}$ For example, Gruber (1997) assumes that the consumption gap of the unemployed is linear in $b$, and that $\gamma$ and the nonemployment duration elasticity do not vary with $b$. While they may be reasonable approximations for levels of $b$ and $P$ that are close to the current economy, they may be quite inaccurate when extrapolating to values further away from the observed values. If exogenous variation over the full range of $\mathrm{b}$ and $\mathrm{P}$ was available, the sufficient statistics approach could be used to trace out the approximate shape of the marginal welfare function. Since this is rarely available, when the optimal level and duration of UI benefits is far away from the current economy, it may be advantageous to use a structural model to extrapolate behavior and welfare parameters out of sample. Yet, despite a sizable literature that estimates structural models of job search, attempts to use such estimated models to calculate the optimal structure of UI benefits have been relatively rare. One exception is Lentz (2009), who estimates a search model using data from Denmark and then uses the model to solve for the optimal level of UI benefits (with infinite durations). In future work, it would be interesting to combine the structural and sufficient statistics approach to explore the optimality of the UI system.
} 
benefits should be extended in recessions. Studying the U.S., Kroft and Notowidigdo (2016) find that the labor supply effect of UI benefits levels also tends to decline in recessions, while the consumption drop upon unemployment weakly increases in recession, and hence come to a similar conclusion. An important caveat to the interpretation of these findings discussed in Section 4.6 is that changes in the welfare effects over the business cycle should depend on the macro, not the micro, labor supply elasticity.

By similar arguments, if exhaustion rates or labor supply effects of UI (or utility parameters) vary substantially in the population, UI benefit durations or levels should vary. Unfortunately, in many cases it is difficult to obtain precise estimates for the variation in labor supply effects in the population, either because of sample sizes, or because the design itself already targets particular demographic groups. For example, none of the studies analyzing discrete UI extensions occurring at different age cutoffs find substantial variation in UI effects by age (e.g., Schmieder et al., 2012a). On the other hand, Michelacci and Ruffo (2015) calibrate a life-cycle model of optimal UI, taking into account human capital formation and argue that unemployment benefits should be more generous for the young, who have low savings and high incentives to find work. Understanding the heterogeneity of UI benefit effects on labor supply and consumption is an area where additional work would be useful.

A particularly interesting case of potential differences in the effect of UI benefits between local labor markets is discussed in Gerard and Gonzaga (2013). A central concern in developing countries is that presence of informal labor markets may lower the costs of receiving UI benefits, and hence may raise the efficiency costs of UI. Gerard and Gonzaga (2013) study the effect of discrete increases in UI durations by job tenure in Brazil. While they confirm that at benefit exhaustion some workers shift from informal to formal work, the effective efficiency cost is minor because reemployment rates in the formal sector are so low. Instead, Gerard and Gonzaga show that the efficiency costs are larger the greater is the share of formal sector employment, because a larger fraction of workers reenter formal employment (and hence UI actually reduces formal sector employment and hence tax revenues). Overall, the paper shows that while the efficiency costs of UI in Brazil are smaller than in the US, a greater fraction of households is likely to be liquidity constrained. 


\subsection{The Optimal Time Path of UI}

Most recent empirical papers concerned with the optimality of the UI system have used the socalled sufficient statistic approach and focused on the marginal welfare effect of a single change in either benefits or durations from the prevailing level. This is consistent with the observation in Section 2 that the majority of UI systems feature a benefit path with a single step-down in benefits. In contrast a sizable, mostly theoretical literature has explored the optimal time path of UI benefits ${ }^{18}$ Yet, this literature has largely relied on numerically solving calibrated models, and has not been tightly linked to the empirical literature. In contrast, in a recent paper Kolsrud et al. (2015) use a sequence of kinks in the benefit schedule to estimate the labor supply effect of UI and the consumption effect of unemployment at different points over the unemployment spell in Sweden. Using a dynamic version of the framework laid out in Section 3, they use these estimates to assess whether the optimal benefit path should increase or decline over the unemployment spell. They find that the consumption drop at unemployment increases over the spell, with little effect of private insurance through savings. In contrast, the behavioral costs derived from the labor supply effects decline over the spell, suggesting that the optimal benefit path should be increasing with unemployment duration.

\subsection{Crowd Out of Private Insurance.}

As with any social insurance program, the presence of UI benefits may crowd out forms of private insurance as well. For example UI benefits can reduce precautionary savings by workers at risk of layoff (Engen and Gruber, 2001), and has been shown to diminishe the rise in spousal labor supply in response to a layoff (Cullen and Gruber, 2000). Similar crowd-out effects may be present for insurance via family transfers or the take up of other social insurance programs available to unemployed workers, such as food stamps (SNAP), or employment subsidies such as the Earned Income Tax Credit. Yet, beyond empirical estimates the welfare

\footnotetext{
${ }^{18}$ In a seminal paper, Shavell and Weiss $(1979)$ showed that the optimal time path of UI benefits without savings is declining over time. Hopenhayn and Nicolini (1997) showed that allowing for a tax upon reemployment alters the optimal time path to be much flatter followed by a reemployment tax that is increasing in the duration of unemployment. However, Pavoni (2007) shows that if the social planner has to maintain a minimum consumption level, the result of an optimal declining benefit path is reestablished and Pavoni (2009) shows that such a minimum consumption level arises endogenously in a model with skill depreciation. If the unemployed have savings at the beginning of the unemployment spell the optimal benefit path may be a constant level of benefits paid indefinitely, as suggested by Kocherlakota (2004) and Shimer and Werning (2008).
} 
consequences of substituting between different types of insurance mechanisms are not fully understood. For example, some forms of private insurance may entail foregoing investments in favor of short-term consumption commitments. In an extreme case, one may observe no change in consumption at job loss, but reductions in investments in human capital, health, or children. The utilization of costly means of private insurance is a particular concern in developing countries, were income shocks may be larger and the social safety net is weaker. For example, Chetty and Looney (2006) document that while unemployment leads to similar reductions in consumption in the United States and Indonesia, the methods of consumption smoothing are very different. As documented by Dynarski and Gruber (1997), unemployed in the U.S. rely chiefly on UI payments (replacing 15 cents for each dollar lost), reductions in tax burden (replacing about 26-35 cents per dollar lost), and reductions in own savings (replacing 35-40 cents per dollar lost). In contrast, in Indonesia reductions in education spending for children, as well as increases in child labor and labor of other household members are more frequent. Even in the U.S., increasing amount of research shows that, despite the presence of more generous UI benefits, job loss can have adverse consequences on health and educational outcomes of children (e.g. von Wachter, 2015), possibly because the majority of unemployed have very little savings (e.g., Dickens et al. (forthcoming)). Incorporating the costs of alternative forms of insurance into the evaluation of the welfare benefits of UI is a useful avenue for future research.19

Another approach to privately reducing the risk of unemployment is to accumulate general human capital. Presence of UI benefits may encourage accumulation of human capital specific to an occupation or industry whose value is more sensitive to economic conditions. While the early literature suggested that by reducing uncertainty UI may raise human capital accumulation (e.g., Brown and Kaufold, 1988), recent papers (e.g., Mukoyama and Şahin, 2006) have suggested that more generous UI favors accumulation of specific skills and may even reduce the incentives to accumulate general human capital. These ideas have been used to argue that more generous UI benefits in Europe have supported a higher degree of specific skill accumulation than in the US, which in turn is purported to have low social insurance and higher degrees of general skills (e.g. Wasmer, 2002). Whether UI actually leads to a "crowd

\footnotetext{
${ }^{19}$ Blundell et al. (2012) contrast the role of spousal labor supply with other mechanisms of insurance, but do not pursue a normative analysis of UI benefit provision.
} 
in" or "crowd out" of human capital, and if so of what kind, are interesting open questions.

\subsection{Spillover Effects of UI Extensions}

The model in Section 3 is a partial equilibrium model that assumes that firms do not respond to changes in UI benefit levels by adjusting vacancy creation and that workers job finding rates do not depend on the actions of other workers. This assumption may not hold, however. For example, if the unemployed compete for a fixed number of jobs (job rationing), the reduction of search intensity by some will lead to an increased likelihood of a job match by others. On the other hand, if the decline in search intensity raises the cost of job creation, the vacancy creation rate may decline in response to more generous UI benefits, augmenting the direct effect of a decline in search intensity on employment.

Landais et al. (2015) develop a model that explicitly allows for such spillover effects in a search and matching model of the labor market. In the model there are two types of spillover effects which both act by affecting labor market tightness (the ratio between job seekers and vacancies): a) firms can respond to UI by increasing or decreasing the numbers of vacancies they create and b) there can be spillover effects between job searchers through crowding effects. The model draws a clear distinction between the micro elasticity of UI $\eta_{D, b}^{\text {micro }}$, which is the effect of benefits on unemployment duration holding tightness constant and the macro elasticity of UI $\eta_{D, b}^{\text {macro }}$, which includes the effects of benefits on durations that come from general equilibrium adjustments in tightness. The macro elasticity is given as the sum of the micro elasticity plus a spillover term that depends on the elasticity of tightness with respect to benefits. The standard Baily-Chetty formula does not capture the full welfare effects of UI, because the individual unemployed will ignore the effects of their own behavior on labor market tightness creating a wedge between the individual's first order condition and the relevant effect of UI on aggregate durations. Landais et al. (2015) provide a modified version of the Baily-Chetty formula that includes an elasticity wedge term: $1-\frac{\eta_{D, b}^{\text {macro }}}{\eta_{D, b}^{\text {micro }}}$. If the wedge terms is equal to zero, the formula coincides with the standard Baily-Chetty formula. If the wedge term is positive, i.e. the macro elasticity is smaller than the micro, then the optimal replacement rate is higher, if it is negative the optimal replacement rate is smaller. Landais et al. (2015) show that the wedge term can be positive or negative, depending on whether increases in UI benefits raise or lower labor market tightness. Since this term can be 
positive or negative under alternative, plausible search models, estimating the wedge (or the ratio of macro to micro elasticities) is an important empirical question ${ }^{20}$

Many of the most convincing recent studies on the effects of UI extensions or changes in benefit levels discussed in section 4.1 come from regression discontinuity and regression kink designs. While these studies provide clean identification of labor supply effects, the estimates are plausible because they hold many factors constant, and in particular compare workers within the same labor market and therefore facing the same labor market tightness (e.g. to the left and right of a policy threshold). Thus these estimates all correspond to micro effects and do not provide information about the macro effects. Study of the macro effects have to allow for adjustments of labor market tightness and therefore have to rely on comparisons across labor markets, which are inherently harder to plausibly identify.

A small but growing literature has tried to assess the potential spillover effects from UI extensions. Using the CPS, Levine (1993) and Valletta (2014) have analyzed the crowding effect of UI extensions for unemployed workers not eligible for UI. They find support for the notion that UI extensions raises the job finding rate of unaffected job seekers. Perhaps the best evidence on spillover effects up to this date can be found in Crépon et al. (2013), who evaluated crowding effects via a randomized social experiment in the context of a large scale job search assistance program in France and find significant evidence for a positive wedge term (macro effects were smaller than micro effects). The strongest evidence on the elasticity wedge of UI estimated consistently within the same setting is offered by Lalive et al. (2015), who evaluate a large scale regional expansion of UI benefits in the 1980s and provide strong evidence of significant spillover effects leading to smaller macro than micro effects.

Several papers have tried to assess the effect of UI benefits on unemployment rates through vacancy creation. Marinescu (2015) uses information from a large online job board to directly assess the effect of UI extensions on vacancies and labor market tightness. While Marinescu (2015) shows that application rates decline in response to UI extensions, she finds little effect on the level or composition of vacancies. She uses the implied effect of UI benefits on labor market tightness to calibrate a macro elasticity, and finds that it is about $30 \%$ smaller than

\footnotetext{
${ }^{20}$ The idea that the ratio between micro and macro labor supply effects is informative about labor market spillovers is also developed in Kroft et al. (2015), who show that the ratio between macro and micro labor force participation effects is informative for the optimal shape of the tax and transfer system in a model with general equilibrium adjustments.
} 
the micro elasticity. Some evidence consistent with this finding is also provided by Kroft et al. (2015) who show that the macro effects are smaller than micro effects in the U.S. for target population of programs like the EITC or welfare benefits.

In contrast, Hagedorn et al. (2013) and Hagedorn et al. (2015) directly study the effect of state-level extensions and contractions in UI benefits on the aggregate unemployment rate. To establish counterfactual unemployment rates, the two papers compare local areas around the borders of states that experienced changes in UI benefits. They find that UI benefit changes can have substantial effects on the aggregate unemployment rate, though this result appears to be somewhat sensitive to the exact sample and specification as Amaral and Ice (2014) argue, and the effects are significantly smaller under some alternative specifications. Coglianese (2016) also studies the macro responses to UI extensions during the Great Recession, using random measurement error in the CPS relative to the true underlying economic conditions as a source of identification, and finds that UI extensions raise employment growth. Coglianese also argues in some detail that the Hagedorn and Manovskii design is likely downward biased. Similarly exploiting measurement error - here identified by later revisions - in the unemployment rates triggering extensions, Chodorow-Reich and Karabarbounis (2016) show that seemingly random variation in UI extensions do not seem to have a significant effect on macroeconomic outcomes. Di Maggio and Kermani (2015) come to similar conclusions using variation in the level of UI benefits across states to argue that the generosity of UI benefits has limited effects on the aggregate unemployment rate. In contrast, Johnston and Mas (2015) study sharp benefit reductions in Missouri. Using a differences-in-differences design, they find a macro effect approximately equal to the implied effect from the micro elasticity (i.e., there are no spillover effects).

Overall, the literature on spillover effects of UI extensions is somewhat mixed with more evidence pointing towards smaller or equal macro than micro effects. More work estimating the spillover effects of UI would be helpful..

Another effect of UI on the aggregate employment rate can arise if the presence of social insurance raises the willingness of firms to fire workers (e.g. Feldstein, 1976, 1978). This mechanism was well understood at the conception of the U.S. UI system, and hence firms' UI tax rates rise with the number of new beneficiaries. However, this so-called experience rating is incomplete, so that firms do not fully internalize the externality their layoffs impose on 
the system. ${ }^{21}$ This was a particular concern in the 1970s and 1980s, were temporary layoffs, followed by recall, were a frequent phenomenon, particularly for the U.S. manufacturing sector. Although temporary layoffs have become less frequent, changes in firms' UI tax rates may also influence permanent layoffs. This is a particularly interesting question, since after the rise in layoffs during Great Recession many firms have likely reached their maximum tax rate and hence the minimum cost of a marginal layoff.

\section{OTHER FRONTIERS IN RESEARCH ON UNEMPLOYMENT INSURANCE}

\subsection{The Effect of UI Extensions on Job Outcomes}

A common motivation for providing UI is to allow unemployed workers to search for good job matches. Intuitively, the notion is that job search is more effective when a worker is unemployed, and taking a low-quality, interim job may hurt the prospect of finding a job that fits a worker's skill level. While there is no heterogeneity in the wage or job type in the basic model sketched out in Section 3, this is easily added by introducing reservation wages. In a canonical model in which workers control both job search intensity and reservation wages, an extension in UI benefits leads to an outward shift of the reservation wage at all unemployment durations. This implies that an increase in UI benefits raises the average starting wage for new jobs. A parallel implication holds for other job characteristics and the quality of a job match, which is often measured by the duration of tenure at new jobs. The implication from the basic model can be reversed if unemployment duration itself has a negative effect on wages, for example if human capital depreciates through the unemployment spell (Schmieder et al., 2016). The presence of negative effects could be rational for forward-looking individuals if the value of leisure is high enough.

A small but growing literature directly evaluates the effect of UI benefits on job outcomes empirically. The overall finding is that UI extensions tend to have small negative effects on wages, but the results are often imprecisely estimated and often include zero or modest positive values in the confidence interval. For example, Schmieder et al. (2016) use a very large sample of individuals to show that an increase in UI durations of 6 months precisely lowers

\footnotetext{
${ }^{21}$ See Krueger and Meyer 2002 for a summary of the evidence.
} 
daily wages by less than one percent. Studies with smaller samples have found comparable point estimates with less precision (e.g., Card et al., 2007a and Lalive (2007) in Austria, van Ours and Vodopivec, 2008 in Slovenia, Centeno and Novo, 2009, in Portugal and Degen and Lalive, 2013, in Switzerland). In contrast, Nekoei and Weber (2015) find a positive relationship between extensions of relatively short baseline UI benefits and reemployment wages in Austria. In line with the literature, they find that nonemployment duration is negatively correlated with wages, and they argue that their findings can be reconciled with those of the rest of literature due to the relatively short UI durations (and hence nonemployment durations) they study. Additional evidence on how the duration of UI benefits affects job outcomes, especially in the U.S., would be helpful. ${ }^{22}$

One important implication of these findings is that it appears that unemployment duration indeed has a causal negative effect on wages. It has been difficult to obtain causal estimates of this effect because unemployment duration is not randomly assigned. Yet, even if one were able to solve the selection problem, reservation wages also change over the non-employment spell, making it difficult to isolate the effect of skill depreciation on wages. Schmieder et al. (2016) show that under certain circumstances, one can indeed interpret the negative effect of UI extensions on wages as human capital depreciation or statistical discrimination. They argue that if reservation wages do not bind, by revealed preference mean reemployment wages at each unemployment duration should be unaffected by UI extensions. They test and find support for this restriction using data from Germany. Lalive et al. (2015) report similar findings for UI extensions in Austria.

Another important question is whether the potential adverse wage effects of UI extensions modify the welfare trade offs discussed in Sections 3 and 4.2. As discussed in Section 3, if workers receive the entire match surplus, then wage declines are effectively already factored in their optimal response to UI benefits and hence do not alter the welfare calculation. There are three exceptions to this conclusion. First, this equivalence result fails if workers share the surplus with their employers - as would be the case under Nash bargaining, for example. Second, there are budgetary consequences if wage effects are strong enough to reduce other tax revenues. Finally, workers might not be forward looking or might be over optimistic regarding

\footnotetext{
${ }^{22}$ The difficulty in the US is that typically only information on quarterly earnings, not wages, is observed in the data. For example, Johnston and Mas (2015) report that UI reductions in Missouri did not have a noticeable effect on quarterly earnings.
} 
how their job prospects change over the unemployment spell.

\subsection{Long-Term Effects of UI Extensions}

Most of the theoretical and empirical work focuses on the short term effects of UI extensions. This is at least in part because empirically it is difficult to analyze longer-term effects with sufficient precision. Yet, there are several potential sources of longer-term effects of UI extensions. One effect already mentioned is human capital depreciation or changes in job quality. Studies of effects of other labor market shocks, such as job losses, suggest that changes in wages or job characteristics can be very persistent. Hence, it is likely that UI-induced changes in employment status or job characteristics might be persistent as well. Another source of variation arises directly from the underlying labor supply decision - if workers use wealth to self-insure against shocks, a temporary reduction in wealth may raise labor supply after the initial nonemployment spell. Yet another source of persistent effects can arise from habituation or knowledge of the program. It has long been posited in the welfare literature that take-up of social assistance programs may be affected by a distaste of, or lack of knowledge of, the program. In that case, initial exposure to the program might yield larger elasticities later on.

The vast majority of the literature analyzes the effect of extensions in UI durations or increases in UI benefits on the duration until a job is found. However, this may either underor overstate the total cost of UI extensions if these also affect the incidence and duration of future unemployment. Schmieder et al. (2012b) study the long-term effect of UI extensions on nonemployment over a 5 year period after entering UI. They find that longer UI benefit durations raise nonemployment for over three years after the initial spell. However, they show that this effect is entirely driven by the initial unemployment spell. The effect of the initial spell on lifetime unemployment is attenuated by future labor supply decisions, since workers with UI extensions spend less time in unemployment after the initial unemployment spell[23

${ }^{23}$ Schmieder et al. (2012b) find that the effect of potential UI benefits $P$ on total nonemployment $(d D / d P$, which in their case is measured over the first 5 years of the nonemployment spell) is smaller than the effect of $P$ on the duration of the initial nonemployment spell $\left(d D^{1} / d P\right.$, which is the marginal effect typically estimated). I.e., the long-term effect of UI on overall nonemployment is smaller. They show that the difference between the two marginal effects consists of three terms:

$$
\frac{d D}{d P}-\frac{d D^{1}}{d P}=-\frac{d D^{1}}{d P} p_{u}+\left(T-D^{1}\right) \frac{d p_{u}}{d P}-\frac{d \operatorname{cov}\left(D^{1}, p_{u}\right)}{d P}
$$


In contrast, Lemieux and MacLeod (2000) find evidence that first-time exposure to a new UI regime leads to a higher propensity to collect UI benefits again in the future. This phenomenon, which they term supply-side hysteresis, could be due to information, a decline in stigma, or habituation. However, since they do not have information on actual nonemployment, it is an open question whether labor supply elasticities actually first fell as UI benefits became more generous, and then recovered, and whether learning is always present for firsttime UI users. For example, Schmieder et al. (2012a) find that adjustment to a benefit reform in Germany is instantaneous among all UI spells, but they do not differentiate between firsttime and previous UI recipients. Another important aspect is that learning about the program could occur for both workers and firms, especially in Canada where firms' UI taxes do not depend on previous UI claims (i.e., there is no experience rating).

\subsection{Behavioral Economics and Unemployment Insurance}

A rapidly growing literature (see Chetty, 2015, for an overview) has documented how insights from behavioral economics can improve public policy making, either by improving the predictive power of economic models or by opening up the possibility of new policy tools. Despite the large influence of behavioral economics in public economics and health, the vast majority of the empirical and theoretical literature on UI has been based on models with standard neoclassical preferences.s This is perhaps surprising given that the discussion in Section 3 implies that non-standard assumptions about risk preferences, discounting, or beliefs are all likely to affect the labor supply and welfare effects of UI benefits. However, a number of recent papers have started to explore how behavioral insights may improve the empirical analysis of job search and shape recommendations for designing UI benefits and these papers can be classified along these three types of deviations.

As a first example of a job search model with nonstandard preferences, DellaVigna and Paserman (2005) explored the implications of relaxing the standard assumption of exponential

where $p_{u}$ is the average probability of being unemployed in a given month after the first nonemployment spell (this is a combination of the probability of being laid off again and the duration of the later unemployment spells). The first term suggests that at a given probability of subsequent unemployment, if the follow-up period is finite, the longer the initial spell, the shorter the time spent in unemployment afterwards. Second, the propensity of spending the remaining time $\left(T-D^{1}\right)$ in unemployment may change. Third, UI benefits may affect the relationship between the initial spell duration and the probability of subsequent unemployment. Schmieder et al. (2012b) show that all three components matter, but that the reduction in the unemployment probability explains more than half of the difference. 
discounting, allowing for hyperbolic discounting as in Laibson (1997). They show that, while impatience in general leads to lower reservation wages and search intensity, with exponential discounting the former effect dominates (at least for sufficiently patient individuals) and the exit hazard should increase with higher impatience. However, with hyperbolic discounting the comparative statics are reversed and the exit hazard falls with impatience. Evidence from the NLSY and the PSID appear to be strongly in line with the predictions from the model with hyperbolic discounting. Paserman (2008) builds on this and estimates a structural job search model with hyperbolic discounting. The estimates point to a substantial degree of present bias ( $\beta$ between 0.4 for low wage workers and 0.89 for high wage workers) and the model provides a significantly improved fit relative to the model with exponential discounting.

As another form of nonstandard preferences, DellaVigna et al. (2016), allow for reference dependence in the utility function, similar to Kahneman and Tversky's (1979) prospect theory. In this model individuals evaluate their current consumption level relative to a reference point, which is given as the average income in the recent past. Many papers have documented that the exit hazard from unemployment typically falls early on in the unemployment spell, rises towards the exhaustion point of UI benefits and then falls again. Reference dependence can rationalize this pattern in a natural way: early on in the unemployment spell individuals search hard given that their benefits are low relative to their recent income. Over time they get used to the lower income, and thus reduce their search effort. As they approach the benefit cut, their search effort rises again, followed by a decline once they get used to the new, even lower, benefit level. To distinguish this model from a standard model with unobserved heterogeneity, DellaVigna et al. (2016) provide evidence from a natural experiment in Hungary that front loaded the UI benefit path. This reform led to a change in the exit hazard that is difficult to explain with the standard model. The paper goes on to estimate the model structurally to show that the standard model is clearly rejected and that the estimates point to substantial reference dependence with a slowly adjusting reference point.

In the class of nonstandard beliefs, Spinnewijn (2014) analyzes how biased beliefs about the job finding probability can affect the design of UI benefits. The paper shows that people systematically underestimate the time it takes to find a job, which would lead them to save too little and to not search enough for jobs. The paper distinguishes between two types of overconfidence: baseline-optimism, where individuals overestimate the level of the job finding 
probability, and control-optimism, where individuals overestimate the effect of search effort on the job finding probability. Spinnewijn (2014) shows that the sufficient statistics approach can be adapted to allow for overconfidence and derives an adjusted Baily-Chetty formula incorporating corrective terms for the biased beliefs. This modified formula shows that the standard unemployment duration elasticity overestimates the cost from reducing search incentives when the unemployed have control-optimistic beliefs. On the other hand the gap in marginal utilities overestimates the welfare gain from providing insurance when job seekers have baseline-optimistic beliefs. This is an interesting example of how the sufficient statistics approach can be used in the context of behavioral economics to provide insights into determining the relevant parameters needed for policy analysis. While the paper provides estimates for baseline-optimism, it is quite difficult to convincingly estimate control-optimism and this should be a fruitful area of future research. A similar idea has been explored by Caliendo et al. (2015), where individuals have different beliefs about the impact of their search effort on the job offer arrival rate. Using the the 'locus of control' concept from psychology, they show that individuals with an internal locus of control search harder and have higher reservation wages than individuals with an external locus of control.

Finally, a few papers have provided evidence of nonstandard decision making, such as through the role of framing, limited attention or emotions, though this literature has been less linked to economic modeling and UI design. For example, Altmann et al. (2015), conducted an experiment where they mailed a letter to a random group of UI entrants. The letter provided some information about benefits of job search, the current economic environment and attempts to frame the period of unemployment in a more positive light. The letter reduced unemployment durations significantly and points towards the importance of at least some of these channels. In a fascinating series of papers, Krueger and Mueller (2010), Krueger et al. (2011), Krueger and Mueller (2012), and Krueger and Mueller (2016) have documented several stylized facts that may, at least at first glance, seem puzzling from the perspective of the standard job search model. For example, job searchers spend on average very little time searching for a job: only around 10 to 20 minutes per day, and even at this low level search effort seems to decline throughout the unemployment spell. Furthermore, it is striking that self reported reservation wages are very close to the pre-unemployment wage for most individuals, yet job seekers often accept jobs that pay below the self reported reservation 
wage. Both of these facts may point to the importance of nonstandard decision making and are worthwhile exploring more. Perhaps an explanation for the low search effort lies in the fact that self-reported happiness is quite low, in particular while looking for a job, and individuals become increasingly depressed throughout the unemployment spell. But if these emotional states play an important role for determining job search, then the standard model may miss some important aspects and the typical tools of incentives, sanctions or search monitoring may have counter intuitive results. Instead, interventions that focus on providing psychological and social support or alternative ways of framing and motivation may be more successful in helping job seekers.

\subsection{Interactions with Other Programs}

The majority of the literature studies exclusively the effect of UI, independent of other programs. However, clearly the UI program typically does not operate in a policy vacuum. Broadly speaking, there are two types of programs UI can interact with. First, there is typically a range of complementary programs aimed specifically at unemployed job seekers (some of these are available to all job seekers, some are specifically targeted to UI recipients). These

include various kinds of job search assistance (JSA), either light or intensive re-training, and sometimes sanctions if suitable jobs are not taken up.

Second, UI also can interact with other social insurance programs, such as welfare programs, food stamps (SNAP), or disability insurance (DI). As discussed in Section 4.1, economists have long understood that UI changes the relative price of insurance for workers, potentially leading to crowd out of self-insurance. In the same fashion, UI may 'crowd out' utilization of other social insurance programs. If the programs are substitutes, this could generate cost savings that should be taken into account in the optimal benefit calculations. Such savings are limited in so far as most social insurance programs are geared towards those with chronic lower income, not more stable workers who are typically receiving UI. However, especially in the case of large recessions, UI extensions may prevent these stable workers from taking up more expensive programs, such as DI.

There have been a reasonable amount of theoretical and empirical papers addressing the interactions between UI and complementary active labor market programs. There is very little work addressing the interaction between UI and social insurance programs more generally. 
Several papers explore the optimal combination of UI-related policies. Since the standard model typically has finite benefit durations, it incorporates a role for the level of second-tier benefits, available in many European countries in form of a means tested "unemployment assistance" program. More sophisticated models incorporate a role for retraining, job search assistance or wage subsidy programs, which are all components of a typical UI "system". For example, Pavoni and Violante (2007) incorporate these components in a principal-agent model, and derive the optimal policy that arises. They show that an optimal sequence of UI, monitored JSA, and welfare arises endogenously, during which benefits are first constant, decline, and then are constant again. An important necessary feature in such a "front loaded" structure is that there is a negative causal effect on unemployment duration on the job finding rates, as can arise if workers experience skill depreciation ${ }^{24}$

There is a large literature analyzing the effect of a range of active labor market programs (ALMP) on employment outcomes of the unemployed in general (e.g. Card et al., 2010, 2015c). Typically, these papers focus on the effectiveness of, say, monitoring, sanctions, JSA or retraining itself, rather than its interaction with parameters of the UI program. Yet, several aspects indicated by the theory are worth further investigation, such as whether the effectiveness of different services varies throughout the UI spell or with economic conditions in the local labor market. For example, Black et al. (2003) find that the threat of reemployment services has a stronger effect on reemployment than the service itself. Yet, this result is established in relatively high-pressure labor markets, and may not hold in situations with slack demand. Schmieder and Trenkle (2015) raise the concern that interactions of UI with other job search programs may lead to biased estimates of the disincentive effect of UI. In typical micro-econometric studies of the effects of UI extensions, it seems possible that UI caseworkers allocate their resources (time, vacancies that can be referred, ALMP, ...) taking UI eligibility into account. If they target these resources either to the unemployed with shorter benefit durations or who are most responsive, this could lead to biased estimates of the effects of UI, even in seemingly clean designs like RDs or RKDs. The paper is reassuring however, in that it presents evidence that along a variety of measures caseworkers do not seem to target resources differentially to unemployed with different eligibility durations.

\footnotetext{
${ }^{24}$ Boone et al. (2007) also analyze the optimal amount of monitoring and sanctions in a context of timelimited UI benefits.
} 
A promising avenue for future work is how UI interacts with other social insurance programs, such as welfare, food stamps (SNAP), or disability insurance. For example, Mueller et al. (2016) have used haphazard extensions in UI benefits during the 2008 recession in the U.S. to analyze the effect of UI benefits on the propensity to apply (and receive) Social Security Disability Insurance (SSDI). Given SSDI is a generous program with a high implicit tax on work and access to costly Medicare benefits, UI extensions could generate substantial cost savings if they helped marginally disabled job losers to remain in the labor force instead of transiting onto SSDI. In contrast to much of the literature suggesting that SSDI may substantially reduce employment of marginally disabled workers, Mueller et al. do not find that more generous UI benefits lower SSDI application rates. The reason is that the vast majority of workers applying to SSDI actually have very low prior labor force attachment, and hence are unlikely to be eligible for UI.

\section{CONCLUSION}

Recent years have seen significant progress in our empirical and theoretical understanding of unemployment insurance. On the one hand, new empirical methods and data sets have greatly improved the plausibility of empirical estimates of the effects of UI. On the other hand theoretical work has highlighted important dimensions of understanding the trade-offs of more generous UI benefits. Yet, while the body of evidence is slowly building up a consistent picture of some specific aspects of UI - such as the labor supply effects of benefit levels and potential benefit durations on unemployment durations - this work has also drawn the spotlight to many areas where our understanding is quite limited, and where it would be important to have more evidence to provide actual policy recommendations for UI design. While these areas are numerous, perhaps some stand out in particular: 1) the welfare gains from UI has only been studied in very limited contexts and not for benefit exhaustees (the crucial group for understanding the trade-off of extending UI benefit duration); 2) despite some creative work, there are still very significant gaps regarding the direction and size of spillover effects and how

they may vary over the business cycle; 3) the evidence on job outcomes, such as reemployment wages, is limited and somewhat conflicting, in particular due to the low power of most studies to detect effects in the relevant range; 4) the effects of UI on outcomes such as spousal labor 
supply, long-term outcomes and uptake of other social programs is understudied; and 5) the analysis of the role of UI in developing economies with large informal sectors is in its infancy, which is particularly important given the sizable interest by many emerging market countries in developing UI systems.

In addition to these open empirical questions, there are some important conceptual questions that have not been fully resolved. One outstanding question is how to combine theory and empirical work to analyze the shape of the welfare function and the optimal UI benefit structure. Another question is what the right framework is in which to model UI effects. Recent papers have moved away from modeling job search in a reservation wage model, at least in part motivated by the lack of evidence for positive effects of UI on reemployment wages. However, models with fixed wages appear at odds with the fact that most labor markets exhibit a large amount of wage dispersion and that workers appear to reject some job offers, in particular if they offer low wages. Related to this, an exciting avenue for future research will be to explore whether job search models can be improved by modeling other features of the search process, for example as suggested by the recent literature seeking to bring in insights from behavioral economics. 


\section{References}

Aaronson, Daniel, Bhashkar Mazumder, and Shani Schechter, "What is behind the rise in long-term unemployment?," Economic Perspectives, (Q II), (2010), 28-51.

Altmann, Steffen, Armin Falk, Simon Jäger, and Florian Zimmermann, "Learning about Job Search: A Field Experiment with Job Seekers in Germany," Technical Report (2015).

Amaral, Pedro and Jessica Ice, "Reassessing the Effects of Extending Unemployment Insurance Benefits," Economic Commentary, 2014-23 (2014).

Baily, Martin Neil, "Some aspects of optimal unemployment insurance," Journal of Public Economics, 10 (3), (1978), 379-402.

Barbanchon, Thomas Le, "The Effect of the Potential Duration of Unemployment Benefits on Unemployment Exits to Work and Match Quality in France," Technical Report (2012).

Black, Dan A., Jeffrey A. Smith, Mark C. Berger, and Brett J. Noel, "Is the Threat of Reemployment Services More Effective than the Services Themselves? Evidence from Random Assignment in the UI System," The American Economic Review, 93 (4), (2003), pp. 13131327.

Blundell, Richard, Luigi Pistaferri, and Itay Saporta-Eksten, "Consumption inequality and family labor supply," Technical Report, National Bureau of Economic Research (2012).

Boone, Jan, Peter Fredriksson, Bertil Holmlund, and Jan C Van Ours, "Optimal Unemployment Insurance with Monitoring and Sanctions*," The Economic Journal, 117 (518), (2007), 399-421.

Brown, Eleanor and Howard Kaufold, "Human Capital Accumulation and the Optimal Level of Unemployment Insurance Provision," Journal of Labor Economics, 6 (4), (1988), pp. 493-514.

Caliendo, Marco, Deborah A Cobb-Clark, and Arne Uhlendorff, "Locus of control and job search strategies," Review of Economics and Statistics, 97 (1), (2015), 88-103.

Card, David and Phillip B Levine, "Extended benefits and the duration of UI spells: evidence from the New Jersey extended benefit program," Journal of Public Economics, 78 (2000), $107-138$.

_, Andrew Johnston, Pauline Leung, Alexandre Mas, and Zhuan Pei, "The Effect of Unemployment Benefits on the Duration of Unemployment Insurance Receipt: New Evidence from a Regression Kink Design in Missouri, 2003-2013," American Economic Review, 105 (5), (2015), 126-30.

_ , David S. Lee, Zhuan Pei, and Andrea Weber, "Inference on Causal Effects in a Generalized Regression Kink Design," Econometrica, 83 (6), (2015), 2453-2483.

_ , Jochen Kluve, and Andrea Weber, "Active Labour Market Policy Evaluations: A MetaAnalysis*," The Economic Journal, 120 (548), (2010), F452-F477.

$\ldots, \ldots$, and _ , "What works? A meta analysis of recent active labor market program evaluations," Technical Report, National Bureau of Economic Research (2015).

_ , Raj Chetty, and Andrea Weber, "Cash-on-Hand and Competing Models of Intertemporal Behavior: New Evidence from the Labor Market," The Quarterly Journal of Economics, (2007), 1511-1560.

_ , _ , and _, "The Spike at Benefit Exhaustion: Leaving the Unemployment System or Starting a New Job?," American Economic Review, 97 (2), (2007), 113-118.

Carter, John, Michel Bédard, and Céline Peyron Bista, "Comparative review of unemploy- 
ment and employment insurance experiences in Asia and worldwide," Technical Report, International Labor Organization (2013).

Centeno, Mário and Álvaro A Novo, "Reemployment wages and UI liquidity effect: a regression discontinuity approach," Portuguese Economic Journal, 8 (1), (2009), 45-52.

Chetty, Raj, "Moral Hazard versus Liquidity and Optimal Unemployment Insurance," Journal of Political Economy, 116 (2), (2008), 173-234.

_ , "Sufficient Statistics for Welfare Analysis: A Bridge Between Structural and Reduced-Form Methods," Annual Review of Economics, 1 (1), (2009), 451-488.

_ , "Behavioral Economics and Public Policy: A Pragmatic Perspective," American Economic Review, 105 (5), (2015), 1-33.

- and Adam Looney, "Consumption smoothing and the welfare consequences of social insurance in developing economies," Journal of Public Economics, 90 (12), (2006), 2351-2356.

Chodorow-Reich, Gabriel and Loukas Karabarbounis, "The Limited Macroeconomic Effects of Unemployment Benefit Extensions," Working Paper 22163, National Bureau of Economic Research April (2016).

Coglianese, John, "Do Unemployment Insurance Extensions Reduce Employment?," mimeo, downloaded Feb 28, 2016 at: http://scholar.harvard.edu/coglianese/publications/dounemployment-insurance-extensions-reduce-employment, (2016).

Congressional Budget Office, "Family Income of Unemployment Insurance Recipients," Policy Brief, March (2004).

Crépon, Bruno, Esther Duflo, Marc Gurgand, Roland Rathelot, and Philippe Zamora, "Do Labor Market Policies have Displacement Effects? Evidence from a Clustered Randomized Experiment," The Quarterly Journal of Economics, 128 (2), (2013), 531-580.

Cullen, Julie Berry and Jonathan Gruber, "Does unemployment insurance crowd out spousal labor supply?," Journal of Labor Economics, 18 (3), (2000), 546-572.

Degen, Kathrin and Rafael Lalive, "How Does a Reduction in Potential Benefit Duration Affect Medium-Run Earnings and Employment?," (2013).

DellaVigna, Stefano and M Daniele Paserman, "Job Search and Impatience," Journal of Labor Economics, 23 (3), (2005).

_ , Attila Lindner, Balázs Reizer, and Johannes F. Schmieder, "Reference-Dependent Job Search: Evidence from Hungary," Working Paper 22257, National Bureau of Economic Research May (2016).

Dickens, Bill T., Robert K. Triest, and Rachel B. Sederberg, "Consequences of Long-term Unemployment for Household Finances," Special Issue of Russell Sage Foundation Journal for the Social Sciences, (forthcoming).

Dynarski, Susan and Jonathan Gruber, "Can Families Smooth Variable Earnings?," Brookings Papers on Economic Activity, 28 (1), (1997), 229-303.

Engen, EM and J Gruber, "Unemployment insurance and precautionary saving," Journal of Monetary Economics, 47 (3), (2001), 545-579.

Farber, Henry S and Robert G Valletta, "Do extended unemployment benefits lengthen unemployment spells? Evidence from recent cycles in the US labor market," Journal of Human Resources, 50 (4), (2015), 873-909.

Feldstein, Martin, "Temporary Layoffs in the Theory of Unemployment," Journal of Political Economy, 84 (5), (1976), pp. 937-958.

_ , "The Effect of Unemployment Insurance on Temporary Layoff Unemployment," The Amer- 
ican Economic Review, 68 (5), (1978), pp. 834-846.

- and James Poterba, "Unemployment insurance and reservation wages," Journal of Public Economics, 23 (1), (1984), 141-167.

Ganong, Peter and Pascal Noel, "How Does Unemployment Affect Consumer Spending?," mimeo, downloaded Feb 28, 2016; http://scholar.harvard.edu/files/ganong/files/ganong_jmp_unemployment_spending.pdf, (2015).

Gerard, François and Gustavo M Gonzaga, "Informal Labor and the Cost of Social Programs: Evidence from 15 Years of Unemployment Insurance in Brazil," Available at SSRN 2289880, (2013).

Gruber, Jonathan, "The Consumption Smoothing Benefits of Unemployment Insurance," The American Economic Review, (1997), 192-205.

Hagedorn, Marcus, Fatih Karahan, Iourii Manovskii, and Kurt Mitman, "Unemployment Benefits and Unemployment in the Great Recession: The Role of Macro Effects," Technical Report, National Bureau of Economic Research (2013).

_ , Iourii Manovskii, and Kurt Mitman, "The Impact of Unemployment Benefit Extensions on Employment: The 2014 Employment Miracle?," Technical Report, National Bureau of Economic Research (2015).

Hendren, Nathaniel, "Knowledge of Future Job Loss and Implications for Unemployment Insurance," Technical Report (2015).

Hopenhayn, Hugo A and Juan Pablo Nicolini, "Optimal unemployment insurance," Journal of political economy, 105 (2), (1997), 412-438.

Johnston, Andrew and Alexandre Mas, "Potential Unemployment Insurance Duration and Labor Supply: The Individual and Market-Level Response to a Benefit Cut," Technical Report, working paper (2015).

Kahneman, Daniel and Amos Tversky, "Prospect theory: An analysis of decision under risk," Econometrica, (1979), 263-291.

Katz, LF and BD Meyer, "The Impact of the Potential Duration of Unemployment Benefits on the Duration of Unemployment," Journal of Public Economics, 41 (1), (1990), 45-72.

Kocherlakota, Narayana R, "Figuring out the impact of hidden savings on optimal unemployment insurance," Review of Economic Dynamics, 7 (3), (2004), 541-554.

Kolsrud, J., Camille Landais, Peter Nilsson, and Johannes Spinnewijn, "The Optimal Timing of Unemployment Benefits: Theory and Evidence from Sweden," Technical Report (2015).

Kroft, Kory and Matthew J. Notowidigdo, "Should Unemployment Insurance Vary With the Unemployment Rate? Theory and Evidence," The Review of Economic Studies, (2016).

_ , Kavan Kucko, Etienne Lehmann, and Johannes F Schmieder, "Optimal Income Taxation with Unemployment and Wage Responses: A Sufficient Statistics Approach," Technical Report (2015).

Krueger, Alan B and Andreas I Mueller, "The lot of the unemployed: a time use perspective," Journal of the European Economic Association, 10 (4), (2012), 765-794.

Krueger, Alan B. and Andreas I. Mueller, "A Contribution to the Empirics of Reservation Wages," American Economic Journal: Economic Policy, 8 (1), February (2016), 142-79.

Krueger, Alan B and Andreas Mueller, "Job search and unemployment insurance: New evidence from time use data," Journal of Public Economics, 94 (3), (2010), 298-307.

- and Bruce D Meyer, "Labor supply effects of social insurance," Handbook of Public Eco- 
nomics, 4 (2002), 2327-2392.

_ , Andreas Mueller, Steven J Davis, and Ayşegül Şahin, "Job search, emotional well-being, and job finding in a period of mass unemployment: Evidence from high frequency longitudinal data [with comments and discussion]," Brookings Papers on Economic Activity, (2011), $1-81$.

Laibson, David, "Golden eggs and hyperbolic discounting," The Quarterly Journal of Economics, (1997), 443-477.

Lalive, Rafael, "Unemployment Benefits, Unemployment Duration, and Post-Unemployment Jobs: A Regression Discontinuity Approach," American Economic Review, 97 (2), (2007), $108-112$.

_, "How do extended benefits affect unemployment duration? A regression discontinuity approach," Journal of Econometrics, 142 (2), (2008), 785-806.

_, Camille Landais, and Josef Zweimüller, "Market Externalities of Large Unemployment Insurance Extension Programs," American Economic Review, 105 (12), December (2015), 3564-96.

_ , Jan Van Ours, and Josef Zweimüller, "How changes in financial incentives affect the duration of unemployment," The Review of Economic Studies, 73 (4), (2006), 1009-1038.

Landais, Camille, "Assessing the Welfare Effects of Unemployment Benefits Using the Regression Kink Design," American Economic Journal: Economic Policy, 7 (4), November (2015), 243-78.

_ , Pascal Michaillat, and Emmanuel Saez, "A Macroeconomic Theory of Optimal Unemployment Insurance," Technical Report (2015).

Lawson, Nicholas, "Fiscal Externalities and Optimal Unemployment Insurance," Available at SSRN 2585059, (2014).

Lemieux, Thomas and W Bentley MacLeod, "Supply side hysteresis: the case of the Canadian unemployment insurance system," Journal of Public Economics, 78 (1), (2000), 139-170.

Lentz, Rasmus, "Optimal unemployment insurance in an estimated job search model with savings," Review of Economic Dynamics, 12 (1), (2009), 37-57.

Levine, Phillip B., "Spillover Effects between the Insured and Uninsured Unemployed," Industrial and Labor Relations Review, 47 (1), (1993), pp. 73-86.

Maggio, Marco Di and Amir Kermani, "The Importance of Unemployment Insurance as an Automatic Stabilizer.," (2015). University of California, Berkeley, mimeo.

Marinescu, Ioana, "The General Equilibrium Impacts of Unemployment Insurance: Evidence from a Large Online Job Board," Technical Report (2015).

Meyer, Bruce D, "Unemployment Insurance and Unemployment Spells," Econometrica, 58 (4), (1990), 757-782.

_ , "Lessons from the US unemployment insurance experiments," Journal of Economic Literature, (1995), 91-131.

_ , "Unemployment and workers' compensation programmes: rationale, design, labour supply and income support," Fiscal Studies, 23 (1), (2002), 1-49.

- and Wallace KC Mok, "Quasi-experimental evidence on the effects of unemployment insurance from New York State," Technical Report, National Bureau of Economic Research (2007).

Michelacci, Claudio and Hernán Ruffo, "Optimal Life Cycle Unemployment Insurance," American Economic Review, 105 (2), (2015), 816-59. 
Moffitt, Robert, "Unemployment Insurance and the Distribution of Unemployment Spells," Journal of Econometrics, (28), (1985), 85-101.

Mueller, Andreas I., Jesse Rothstein, and Till M. von Wachter, "Unemployment Insurance and Disability Insurance in the Great Recession," Journal of Labor Economics, 34 (S1), (2016), S445-S475.

Mukoyama, Toshihiko and Ayşegül Şahin, "Specialization and Human Capital in Search Equilibrium," Journal of the European Economic Association, 4 (2/3), (2006), pp. 503-512.

Nekoei, Arash and Andrea Weber, "Does Extending Unemployment Benefits Improve Job Quality?," Technical Report (2015).

OECD, "Benefits and Wages Statistics," (2015). Accessed November 20th, 2015 at http://www.oecd.org/els/benefits-and-wages-statistics.htm.

Paserman, M Daniele, "Job search and hyperbolic discounting: Structural estimation and policy evaluation*," The Economic Journal, 118 (531), (2008), 1418-1452.

Pavoni, Nicola, "On optimal unemployment compensation," Journal of Monetary Economics, 54 (6), (2007), 1612-1630.

_, "Optimal Unemployment Insurance, with Human Capital Depreciation, and Duration Dependence," International Economic Review, 50 (2), (2009), 323-362.

- and Giovanni L Violante, "Optimal welfare-to-work programs," The Review of Economic Studies, 74 (1), (2007), 283-318.

Rothstein, Jesse, "Unemployment Insurance and Job Search in the Great Recession.," Brookings Papers on Economic Activity, (2), (2011).

Rothstein, Jesse; and Robert G. Valletta, "Scraping By: Income and Program Participation After the Loss of Extended Unemployment Benefits," IZA Discussion Papers, (8022), (2014).

Schmieder, Johannes F and Simon Trenkle, "Disincentive Effects of Unemployment Benefits and the Role of Caseworkers," Technical Report (2015).

_ , Till von Wachter, and Stefan Bender, "The Effects of Extended Unemployment Insurance Over the Business Cycle: Evidence from Regression Discontinuity Estimates Over 20 Years," The Quarterly Journal of Economics, 127 (2), (2012), 701-752.

_ , _ , and _ , "The Long-Term Effects of UI Extensions on Employment," The American Economic Review, (2012), 514-519.

Schmieder, Johannes F., Till von Wachter, and Stefan Bender, "The Effect of Unemployment Benefits and Nonemployment Durations on Wages," American Economic Review, 106 (3), March (2016), 739-77.

Shavell, Steven and Laurence Weiss, "The optimal payment of unemployment insurance benefits over time," The Journal of Political Economy, (1979), 1347-1362.

Shimer, Robert and Iván Werning, "Reservation Wages and Unemployment Insurance," The Quarterly Journal of Economics, (2007), 1145-1185.

- and Ivan Werning, "Liquidity and Insurance for the Unemployed," American Economic Review, 98 (5), (2008), 1922-42.

Solon, Gary, "Work incentive effects of taxing unemployment benefits," Econometrica: Journal of the Econometric Society, (1985), 295-306.

Spinnewijn, Johannes, "Unemployed but optimistic: Optimal insurance design with biased beliefs," Journal of the European Economic Association, (2014).

Valletta, Robert, "Recent extensions of U.S. unemployment benefits: search responses in al- 
ternative labor market states," IZA Journal of Labor Policy, 3 (1), (2014), 18. An erratum has been published for this article, http://www.izajolp.com/content/4/1/8.

van Ours, Jan and Milan Vodopivec, "Does reducing unemployment insurance generosity reduce job match quality?," Journal of Public Economics, 92 (3-4), (2008), 684-695.

von Wachter, Till, "Measuring the Cost of Job Displacement in Terms of Worker and Family Outcomes," Technical Report, working paper (2015).

Wasmer, Etienne, "Interpreting Europe and US Labor Markets Differences: The Specificity of Human Capital Investments," (2002). 
Table 1: Estimates of the Effects of Potential Benefit Durations on Unemployment Durations

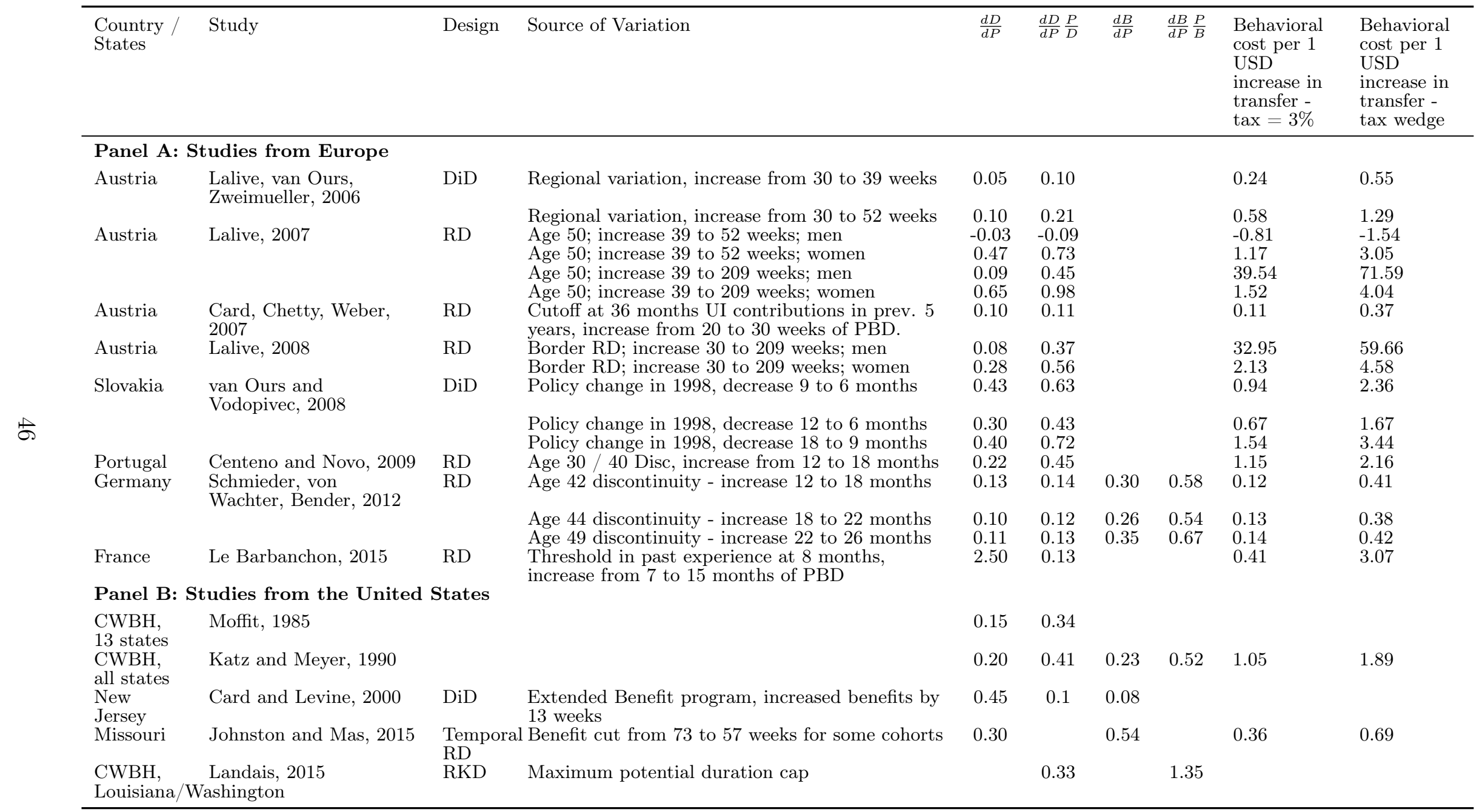

Notes: All calculated behavioral cost terms use the constant hazard approximation described in Section 4.2. The behavioral cost in the last column represents the extra cost (in dollars) to the government budget of increasing the mechanical transfer (that is the transfer in the absence of behavioral responses) to the unemployed by 1 dollar. For example, a behavioral cost of $\$ 0.55$ suggests that to finance a $\$ 1$ transfer from a benefit extension one has to raise $\$ 1.55$ to cover the mechanical cost $(\$ 1)$ and behavioral cost $(\$ 0.55)$. The last two columns differ in whether the budget shortfall is measured using the employee's UI contribution rate (at 3 
Table 2: Estimates of the Effects of Benefit Increases on Unemployment Durations

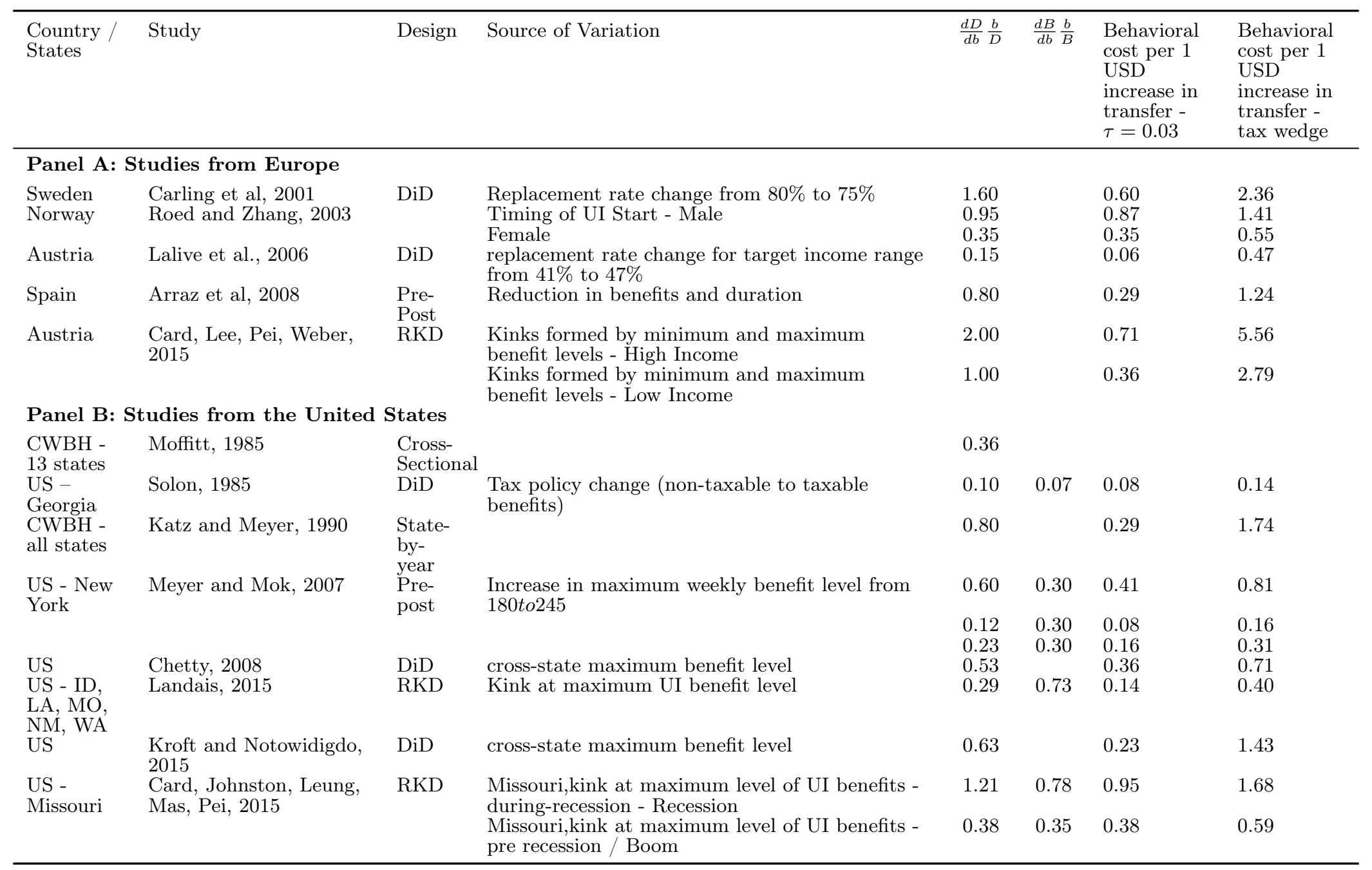

Notes: See notes to Table 1. 
Table 3: Estimates of Consumption Loss at Unemployment and Ratio of Liquidity to Moral Hazard Effect of UI

\begin{tabular}{|c|c|c|c|c|c|c|}
\hline Study & $\begin{array}{l}\text { Range of } \\
\text { Years }\end{array}$ & Country & Data Source & $\begin{array}{l}\text { Consumption } \\
\text { Loss at } \\
\text { Unemployment }\end{array}$ & $\begin{array}{l}\text { Implied Welfare } \\
\text { Effect, CRRA } \\
\text { coefficient } \gamma=2\end{array}$ & $\begin{array}{l}\text { Implied Welfare } \\
\text { Effect, CRRA } \\
\text { coefficient } \gamma=5\end{array}$ \\
\hline \multicolumn{7}{|c|}{ Panel A: Consumption Loss Estimates } \\
\hline Cochrane, 1991 & 1980-1983 & USA & PSID & $24-27 \%$ & 0.51 & 1.275 \\
\hline Gruber, 1997 & $1968-1987$ & USA & PSID, Food only & $6.8 \%$ & 0.136 & 0.34 \\
\hline $\begin{array}{l}\text { Browning and Crossley, } \\
2001\end{array}$ & 1995 & Canada & COEP Canada & $14.0 \%$ & 0.28 & 0.7 \\
\hline Stephens, 2001 & 1968-1992 & USA & PSID & $9.0 \%$ & 0.18 & 0.45 \\
\hline $\begin{array}{l}\text { Chetty and Looney, } \\
2006\end{array}$ & $1980-1993$ & USA & PSID & $10.6 \%$ & 0.212 & 0.53 \\
\hline Chetty and Szeidl, 2007 & 1968-1997 & USA & PSID & $10-15 \%$ & 0.25 & 0.625 \\
\hline \multirow{2}{*}{$\begin{array}{l}\text { Rothstein and Valletta, } \\
2014\end{array}$} & 2001 panel & USA & SIPP & $10.0 \%$ & 0.2 & 0.5 \\
\hline & 2008 panel & USA & SIPP & $20.0 \%$ & 0.4 & 1 \\
\hline $\begin{array}{l}\text { Kroft and Notowididgo, } \\
2015\end{array}$ & $1968-1997$ & USA & PSID & $6.9 \%$ & 0.138 & 0.345 \\
\hline Ganong, 2015 & $2012-2015$ & USA & $\begin{array}{l}\text { JPMCI Checking } \\
\text { account data }\end{array}$ & $6.1 \%$ & 0.122 & 0.305 \\
\hline Kolsrud et al., 2015 & $1999-2007$ & Sweden & Tax Records & $19.0 \%$ & 0.38 & 0.95 \\
\hline \multicolumn{7}{|c|}{ Panel B: Estimates of Liquidity to Moral Hazard Ratio } \\
\hline & & & & \multicolumn{2}{|c|}{$\begin{array}{c}\text { Design to Estimate } \\
\text { Liquidity / Moral Hazard Effect }\end{array}$} & $\begin{array}{l}\text { Liquidity to } \\
\text { Moral Hazard }\end{array}$ \\
\hline $\begin{array}{l}\text { Card, Chetty, Weber, } \\
2007\end{array}$ & $1981-2001$ & Austria & Social Security Registry & \multicolumn{2}{|c|}{ Response to Severance Pay, RD } & 1.4 \\
\hline Chetty, 2008 & $1985-2000$ & USA & SIPP & \multirow{2}{*}{\multicolumn{2}{|c|}{$\begin{array}{c}\text { Response to Severance Pay, OLS } \\
\text { Regression Kink Design }\end{array}$}} & 1.5 \\
\hline Landais, 2015 & 1970 s to 1984 & USA & CWBH (5 States) & & & 0.88 \\
\hline
\end{tabular}

Notes: The implied welfare effect is calculated by multiplying the consumption loss at unemployment by the CRRA coefficient, see text. To calculate implied welfare effect for studies giving range of estimates the midpoint of the interval is taken. 